\title{
Microbiota facilitates the formation of the aminated metabolite of green tea polyphenol (-)-epigallocatechin-3-gallate which trap deleterious reactive endogenous metabolites
}

\author{
Shuwei Zhang ${ }^{1}$, Yantao Zhao ${ }^{1}$, Christina Ohland ${ }^{2}$, Christian Jobin ${ }^{2}$, and Shengmin Sang ${ }^{1, *}$ \\ ${ }^{1}$ Laboratory for Functional Foods and Human Health, Center for Excellence in Post-Harvest \\ Technologies, North Carolina Agricultural and Technical State University, North Carolina \\ Research Campus, 500 Laureate Way, Kannapolis, North Carolina, 28081, USA \\ 2Department of Infectious Diseases and Immunology, University of Florida, Gainesville, Florida, \\ 32611, USA
}

\begin{abstract}
The in vivo mechanism of tea polyphenol-mediated prevention of many chronic diseases is still largely unknown. Studies have shown that accumulation of toxic reactive cellular metabolites, such as ammonia and reactive carbonyl species (RCS), is one of the causing factors to the development of many chronic diseases. In this study, we investigated the in vivo interaction between (-)-epigallocatechin-3-gallate (EGCG), the most abundant polyphenol in tea leaves, and ammonia and RCS. We found that EGCG could be oxidized to EGCG quinone in mice, and then rapidly react with ammonia to generate the aminated EGCG metabolite, 4'- $\mathrm{NH}_{2}$-EGCG. Both EGCG and its aminated metabolite could further scavenge RCS, such as methylglyoxal (MGO), malondialdehyde (MDA), and trans-4-hydroxy-2-nonenal (4-HNE), to produce the RCS conjugates of EGCG and the aminated EGCG. Both the aminated and the RCS conjugated metabolites of EGCG were detected in human after drinking four cups of green tea per day. By comparing the levels of the aminated and the RCS conjugated metabolites in EGCG exposed germ-free (GF) mice and specific-pathogen-free (SPF) mice, we demonstrated that gut microbiota facilitate the formation of the aminated metabolite of EGCG, the RCS conjugates of EGCG, and the RCS conjugates of the aminated EGCG. By comparing the trapping capacities of EGCG and its aminated metabolite under aerobic and anaerobic conditions, we found that oxygen is not essential for the trapping of reactive species by EGCG and 4'- $\mathrm{NH}_{2}$-EGCG suggesting that EGCG and its aminated metabolite could scavenge RCS in the GI track and in the circulation system. Altogether, this study provides in vivo evidences that EGCG has the capacity to scavenge toxic
\end{abstract}

\footnotetext{
*Corresponding Author. Tel: 704-250-5710. Fax: 704-250-5709.

Supporting information

NMR spectra of 4'-NH2-EGCG.

The authors declare no competing financial interest.

Publisher's Disclaimer: This is a PDF file of an unedited manuscript that has been accepted for publication. As a service to our customers we are providing this early version of the manuscript. The manuscript will undergo copyediting, typesetting, and review of the resulting proof before it is published in its final citable form. Please note that during the production process errors may be discovered which could affect the content, and all legal disclaimers that apply to the journal pertain.
} 
reactive metabolic wastes. This finding opens a new window to understand the underlying mechanisms by which drinking tea could prevent the development of chronic diseases.

\section{Graphical abstract}

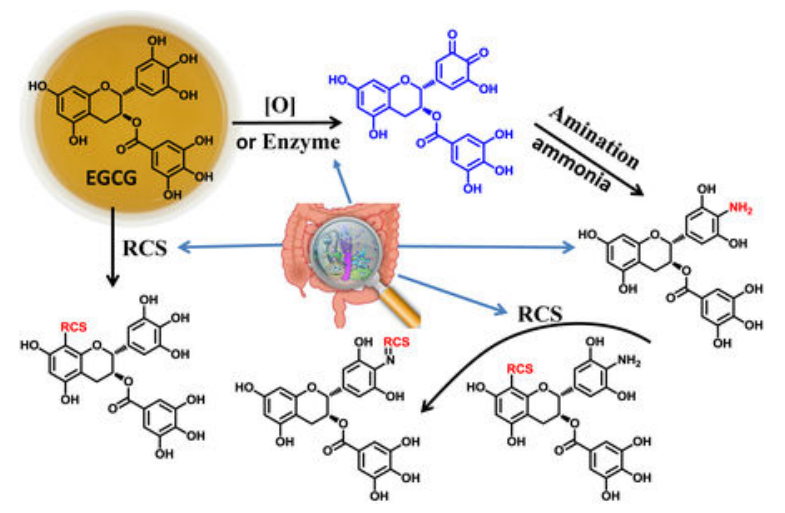

\section{Keywords}

green tea; EGCG; amination; reactive carbonyl species; gut microbiota

\section{Introduction}

(-)-Epigallocatechin-3-gallate (EGCG), representing 50-80\% of the total catechins in tea, is believed to be the most bioactive catechin in green tea [1]. Numerous in vitro and in vivo studies have shown that EGCG effectively prevented many different chronic diseases which include different type of cancers: colon cancer [2], skin cancer [3], prostate cancer [4], breast cancer [5], and other cancers [6]; metabolic syndromes: obesity and diabetes [7-9]; aging related diseases like Alzheimer's disease [10-12]; and cardiovascular disease [13]. As the mechanisms of action of EGCG, numerous reports identified oxidative stress, inflammation, and different molecular signaling pathways as the targets of EGCG [14]. However, most of these targets have not been confirmed in humans.

Increasing evidence showed that the highly reactive species from endogenous or exogenous sources were closely related to many diseases [15-17]. These reactive species include reactive oxygen species (ROS), ammonia, reactive carbonyl species (RCS), such as methylglyoxal (MGO), glyoxal (GO), malondialdehyde (MDA), and 4-hydroxy-trans-2nonenal (4-HNE).

Ammonia, mainly produced in the gut, is a waste product of cellular metabolism. In the colon, the major source of ammonia was from the breakdown of urea by intestinal bacteria which contain urease, and in the small intestine, phosphate-activated glutaminase (PAG) catalyzes the hydrolysis of glutamine to yield glutamate as well as ammonia [15, 16]. Ammonia is central in the pathological process contributing to alteration in neurotransmission, oxidative stress, and cerebral edema and astrocyte swelling in hepatic encephalopathy (also refer to hyperammonemia) which is related to liver failure [15]. 
Carbonyl stress is the abnormal accumulation of RCS that leads to the increased modification of protein and DNA, and contributes to cell and tissue dysfunction in ageing and diseases [17]. Highly reactive dicarbonyl metabolites such as MGO and GO often mediate carbonyl stress in physiological systems. In patients with both type I and type II diabetes, the concentrations of MGO and GO are 2-4 fold higher than in healthy people [18-20]. Although the enhanced formation of glycated proteins was initially associated with diabetes, it is now recognized that this protein modification is also increased during normal aging and is exacerbated in age-dependent neurodegenerative diseases [21-23]. High MGO levels in brain or the circulation are linked to cognitive decline in elderly subjects [24-26]. Many food products and beverages, such as cookies, breads, honeys, coffee, wine, and carbonated soft drinks, as well as cigarette smoke represent exogenous sources of these reactive dicarbonyl species [27-29].

MDA and 4-HNE, the two major lipid peroxidation products of omega-6 fatty acids, are considered as possible causal agents of numerous diseases, such as chronic inflammation, neurodegenerative diseases, cardiovascular diseases, diabetes, and different types of cancer $[30,31]$. MDA and 4-HNE have been widely used as the bioactive markers of lipid peroxidation and oxidative stress in clinical and animal studies [32, 33].

The gut microbiota presenting in our GI tract plays a crucial role in human health [34-36]. They synthesize and modify metabolites that are produced by the host, and produce metabolites from dietary components, some of which are beneficial and others harmful to human health [36]. For example, the major source of ammonia in colon is produced from bacteria related urease $[15,16]$, and MGO could be synthesized from dihydroxyacetone phosphate by methylglyoxal synthase in many bacteria [37].

Theoretically, elimination of these damaging metabolites could lead to the prevention of many chronic diseases. It has been reported that EGCG could scavenge these reactive metabolites under in vitro conditions. In our previous study, we found that the major catechins in green tea and theaflavins in black tea could efficiently trap MGO/GO under physiological conditions [38, 39]. Others have also demonstrated that EGCG could trap lipid peroxidation-derived agents under simulated physiological conditions [30, 40]. However, no evidence has shown that EGCG could work in vivo to eliminate these damaging molecules, either in animals or in humans. In the present study, we investigated the formation of the EGCG conjugates of these reactive species in mice and in humans. In addition, the impact of gut microbiota on the elimination of these toxic reactive species was investigated in germ free (GF) vs. special pathogen free (SPF) mice.

\section{Materials and Methods}

\subsection{Materials}

EGCG, (-)-epicatechin (EC), (-)-epigallocatechin (EGC), and (-)-epicatechin gallate (ECG) were purchased from Synnavator Inc (Durham, NC). Lipton Pure Green Tea bags were purchased from Walmart local store (Kannapolis, NC). L-Ascorbic acid, sodium acetate, ammonium hydroxide solution, methylglyoxal solution (MGO, 40\%), malondialdehyde tetrabutylammonium salt (MDA), and sulfatase from Aerobacter aerogenes and $\beta$ - 
glucuronidase from Helix aspersa were purchased from Sigma (St. Louis, MO). 4Hydroxy-2-nonenal (4-HNE) was purchased from Cayman Chemical (Ann Arbor, MI). Potassium phosphate buffer (PBS, $100 \mathrm{mM}, \mathrm{pH}$ 7.4), 2,4-dinitrophenylhydrazine (DNPH), and $o$-phenylenediamine (OPD) were purchased from Thermo Fisher Scientific (Waltham, MA). $d_{\sigma}$-Dimethyl sulfoxide ( $d_{\sigma}$-DMSO) was purchased from Alfa Aesar (Ward Hill, MA). SPE was performed by Gilson GX-274 system with ASPEC HLB SPE column (Middleton, WI). Other common chemicals and solvents were purchased from VWR International (Radnor, PA). HPLC-grade solvents were obtained from VWR International (Radnor, PA). LC-MS-grade solvents were obtained from Thermo Fisher Scientific (Waltham, MA). HCT-116 and HT-29 human colon cancer cells were obtained from American Type Tissue Culture (Manassas, VA). McCoy's 5A medium was purchased from Thermo Fisher Scientific (Waltham, MA). Fetal bovine serum (FBS) and penicillin/streptomycin were purchased from Gemini Bio-Products (West Sacramento, CA). MTT (3-(4,5dimethylthiaxol-2-yl)-2,5-diphenyltetrazolium bromide) was purchased from CalbiochemNovabiochem (San Diego, CA). Lipopolysaccharide (Escherichia coli O111:B4), Griess reagent (modified), and sodium nitrite were purchased from Sigma Chemical (St. Louis, MO). Antibodies against iNOS and $\beta$-actin were obtained from Cell Signaling Technology (Danvers, MA, USA).

\subsection{Animal Experiments}

\subsubsection{Experiments with CD-1 mice}

2.2.1.1 Animal and diet: Metabolic fate experiments with CD-1 mice were conducted according to a protocol approved by the Institutional Animal Care and Use Committee of the North Carolina Research Campus (IACUC\# 16-016). Male CD-1 mice were purchased from the Charles River (Wilmington, MA) and acclimated for at least 1 week before being randomly assigned to different experimental groups. The mice were housed (5 mice/cage) and maintained in air-conditioned quarters with a room temperature of $20 \pm 2{ }^{\circ} \mathrm{C}$, relative humidity of $50 \pm 10 \%$, and a light-dark cycle of 12:12 hours ( 7 am to $7 \mathrm{pm}$ ). The mice were allowed free access to water and were fed with chow diet. All the mice were washed out for three days by feeding the AIN-93G purified diet before treatment.

\subsubsection{Experimental design}

Experiment-1.: After fasting overnight, one group of CD-1 mice were administered EGCG $(50 \mathrm{mg} / \mathrm{mL}$ in $50 \% \mathrm{DMSO} /$ water) by oral gavage at the dose of $200 \mathrm{mg} / \mathrm{kg}$ body weight. Another group were treated with the same volume vehicle (50\% DMSO/water). After oral gavage, they were moved into two metabolic cages, respectively, to collect the urine and stool for 24 hours. The urine and stool were stored at $-80{ }^{\circ} \mathrm{C}$ before analysis.

Experiment-2.: After identification of the new aminated EGCG metabolite, 4'- $\mathrm{NH}_{2}-\mathrm{EGCG}$ (2), one group of mice was administered the chemical synthesized 4'- $\mathrm{NH}_{2}$-EGCG (2) (50 $\mathrm{mg} / \mathrm{mL}$ in $50 \% \mathrm{DMSO} /$ water) by oral gavage at the dose of $200 \mathrm{mg} / \mathrm{kg}$ body weight, and the urine and stool were collected in the metabolic cage for 24 hours and stored at $-80^{\circ} \mathrm{C}$ before analysis. 


\subsubsection{Germ-free experiment}

Experiment-3.: Experiment was carried out according to the protocol approved by the Institutional Animal Care and Use Committee at the University of Florida (IACUC\# 201609606). 10-14-week old WT 129/SvEv mice were transferred from GF isolators to regular housing and either gavaged with SPF microbiota 2 weeks prior to experiment (SPF) or put in metabolic cages within $12 \mathrm{~h}$ of transfer (GF). Mice were individually housed in mouse metabolic cages (Tecniplast 3600M021) and fasted overnight. Mice were then orally gavaged with $200 \mathrm{mg} / \mathrm{kg}$ EGCG and given autoclaved, powdered food (Teklad $18 \%$ protein, 2018SXM) for the duration of the experiment. After $24 \mathrm{~h}$, feces were frozen and mice were euthanized.

\subsubsection{Preparation of mouse samples.}

Fecal samples.: After drying by compressed nitrogen, the feces were mashed and mixed completely, then $50 \mathrm{mg}$ of the mouse fecal samples were homogenized with $500 \mathrm{~mL}$ of $80 \%$ aqueous methanol containing $0.1 \%$ formic acid and extracted by ultrasonication for $30 \mathrm{~min}$. After centrifugation at $16100 \times \mathrm{g}$ for $15 \mathrm{~min}$ at $4^{\circ} \mathrm{C}$, the supernatants were analyzed by LCMS. For fecal samples from the GF/SPF experiment, fecal samples from each mouse were weighed $50 \mathrm{mg}$ in triplicate and extracted with $500 \mu \mathrm{L}$ of $80 \%$ methanol separately, and the supernatants were analyzed by LC-MS directly with SRM (selected reaction motoring) mode. The peak areas of the target metabolites were extracted and compared between GF and SPF mouse fecal samples.

Urinary samples.: The frozen urinary samples were taken out of the $-80^{\circ} \mathrm{C}$ freezer and thawed at room temperature for approximately $1 \mathrm{~h}$. Enzymatic deconjugation of the urinary samples was conducted according to our previously published method [41]. The reaction solution was passed through ASPEC HLB SPE column by eluting with water to remove the enzymes, proteins, and salts in urine, and the metabolites were collected by eluting with methanol. Then the eluents were dried by compressed nitrogen and re-dissolved in $50 \mu \mathrm{L}$ of $80 \%$ methanol and analyzed by LC-MS.

\subsection{Human experiment}

2.3.1. Subjects-The Institutional Review Board approved the protocol for human experimentation through the Protection of Human Subjects in Research at North Carolina Agricultural and Technical State University (IRB\# 15-0168). Two healthy male volunteers (30-39 years old, weighing 50-80 kg, nonsmokers) participated in the study. Volunteers were informed of the purposes and risks of the study, and written informed consent was obtained. They had not taken antibiotics for at least 6 months prior to the study and had avoided polyphenol-rich foods for at least $72 \mathrm{~h}$ before experiment.

2.3.2 Study design-After washout, overnight urinary and fecal samples were collected before drinking green tea as blank control. At 9:00 am, the first bag of Lipton green tea was brew with $300 \mathrm{~mL}$ of hot water and consumed in $1 \mathrm{~h}$. Then another three bags were brewed with $300 \mathrm{~mL}$ of hot water, separately, and consumed in $1 \mathrm{~h}$ at 12:00 pm, 3:00 pm, and 6:00 $\mathrm{pm}$. They continued consuming green tea over a period of four days. During these days, they avoided consuming coffee or tea that we did not provide. On the fourth day, $24 \mathrm{~h}$ urinary and 
fecal samples were collected after consuming the first cup of tea, and stored at $-80{ }^{\circ} \mathrm{C}$ before analysis

2.3.3 Preparation of human samples-After collection, the urinary samples collected within $24 \mathrm{~h}$ were mixed completely and $1 \mathrm{~mL}$ was used for hydrolysis. The fecal samples collected within $24 \mathrm{~h}$ were smashed and mixed completely, and 10 grams of fecal samples was extracted with $50 \mathrm{~mL}$ of $80 \%$ aqueous methanol for three times. After being dried by a rotavapor, the extract was resuspended in $10 \mathrm{~mL}$ of $50 \mathrm{mM} \mathrm{NaOAc}(\mathrm{pH}$ 5.0). 1 $\mathrm{mL}$ of extract was used for hydrolysis. The urinary and fecal samples were de-conjugated and passed through ASPEC HLB SPE column according to the procedure for mouse samples. Finally, the methanol filtrates from SPE were re-dissolved in $100 \mu \mathrm{L}$ of $80 \%$ aqueous methanol for LC-MS analysis.

\subsection{Cell Experiment}

\subsubsection{Growth inhibitory effects of EGCG and 4'- $\mathrm{NH}_{2}-\mathrm{EGCG}$ on human colon cancer cells.-Cell growth inhibition was determined by a MTT colorimetric assay.} Human colon cancer cells HCT-116 and HT-29 were plated in 96-well microplates with 5000 cells/well and allowed to attach for $24 \mathrm{~h}$ at $37^{\circ} \mathrm{C}$. The test compounds were added to cell culture medium to the desired final concentrations. After the cells were cultured for 48 $\mathrm{h}$, the medium was aspirated, and cells were treated with $200 \mu \mathrm{L}$ of fresh medium containing $2.41 \mathrm{mmol} / \mathrm{L}$ MTT reagent. After incubation for $3 \mathrm{~h}$ at $37^{\circ} \mathrm{C}$, the medium containing MTT was aspirated, $100 \mu \mathrm{L}$ of DMSO was added to solubilize the formazan precipitate, and the plates were shaken gently for an hour at room temperature. Absorbance values were derived from the plate reading at $550 \mathrm{~nm}$ on a Biotek microtiter plate reader. The reading reflected the number of viable cells and was expressed as a percentage of viable cells in the control. Both HCT-116 and HT-29 cells were cultured in McCoy's 5A medium. All of the above media were supplemented with $10 \%$ fetal bovine serum, $1 \%$ penicillin/streptomycin, and $1 \%$ glutamine and the cells were kept in a $37{ }^{\circ} \mathrm{C}$ incubator with $95 \%$ humidity and $5 \% \mathrm{CO}_{2}$. $\mathrm{IC}_{50}$ values were obtained using GraphPad Prism (GraphPad Software, San Diego, CA).

\subsubsection{Effects of EGCG and 4'-NH $\mathrm{NH}_{2}$-EGCG on LPS-induced nitrite level in RAW} 264.7 cells. - The murine macrophage cell line RAW 264.7 was obtained from the American Type Culture Collection (TIB-71; Rockville, MD) and cultured in ATCCformulated Dulbecco's Modified Eagle's Medium (DMEM) supplemented with 10\% fetal bovine serum (FBS). Cells were pre-incubated with different doses of EGCG and 4'- $\mathrm{NH}_{2}-$ EGCG at $0,12.5,25$, and $50 \mu \mathrm{M}$ for $1 \mathrm{~h}$, and then treated with LPS $(100 \mathrm{ng} / \mathrm{mL})$ and EGCG and 4'- $\mathrm{NH}_{2}$-EGCG at the different doses for another $23 \mathrm{~h}$. The nitrite concentration in the culture medium was measured as an indicator of NO production using Griess reagent. One hundred microliters of each supernatant were mixed with the same volume of Griess reagent. The mixture was incubated at room temperature for $15 \mathrm{~min}$, and the absorbance at $540 \mathrm{~nm}$ was measured in a microplate reader (Synergy 2, Biotek). Fresh culture medium was used as a blank. The concentration of NO was calculated based on a standard curve of sodium nitrite in the assay. 
2.4.3 Western blot assay-RAW 264.7 cells were seeded in $100 \mathrm{~mm}$ dishes. After 24 $\mathrm{h}$ treatments, cells were scraped into centrifuge tubes and washed in cold phosphate-buffered saline (PBS) and centrifuged to get pellets. The cell pellets were then lysed using lysis buffer (Cell Signaling, Danvers, MA) containing phosphatase inhibitor cocktails (Sigma Chemical, St. Louis, MO). Protein concentration was determined using a Bradford Protein assay (BioRad). Aliquots containing $20 \mu \mathrm{g}$ protein were loaded onto a $10 \%$ sodium dodecyl sulfatepolyacrylamide gel, transblotted onto a polyvinylidene difluoride (PVDF) membrane (Bio-Rad), blocked with Tris-buffered saline with 1\% Casein with 0.1\% Tween-20, and then incubated with each of the primary antibodies of iNOS (D6B6S, \#13120, Cell signaling, Danvers, MA) and $\beta$-actin (\#4970, Cell signaling, Danvers, MA). The membrane was then incubated with horseradish peroxidase conjugated IgG (Cell signaling, Danvers, MA). The bound complexes were detected with Super Signal Chemiluminescent Subtract (Thermo Scientific, Rockford, IL). The immunoblot bands were quantified by densitometry analysis using Image $J$, and the ratio to $\beta$-actin was calculated and presented, setting the value of control as 1 .

\subsection{In vitro chemical reactions}

\subsubsection{Chemical synthesis and purification of 4'-NH - $^{-E G C G-E G C G ~(100 ~ m g) ~}$} was mixed with $10 \mathrm{~mL}$ of $25 \%$ ammonium hydroxide. The solution was stirred for $60 \mathrm{~min}$ at room temperature. The reaction was stopped by acidification with $2 \mathrm{M} \mathrm{HCl}$ to $\mathrm{pH} 5.0$. The resulting solution was partitioned with ethyl acetate, and the ethyl acetate layer was dried and re-dissolved in $1 \mathrm{~mL}$ of methanol. The final product was purified by preparative HPLC. The purified final product $(28 \mathrm{mg}$ ) was analyzed by LC-MS and NMR.

2.5.2 Nuclear Magnetic Resonance (NMR) analysis- ${ }^{1} \mathrm{H}-$ and ${ }^{13} \mathrm{C}-\mathrm{NMR}$, and twodimensional (2D) NMR spectra were recorded on a Bruker AVANCE $600 \mathrm{MHz}$ spectrometer

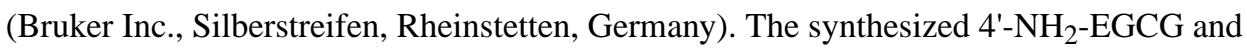
EGCG were analyzed in $d_{\sigma}$-DMSO. Multiplicities are indicated by s (singlet), d (doublet), and dd (double doublet). The ${ }^{13} \mathrm{C}$-NMR spectra are proton decoupled.

\subsubsection{Trapping efficacy studies of MGO and MDA by EGCG and 4'-NH ${ }_{2}$-EGCG under simulated physiological conditions-MGO $(200 \mu \mathrm{M})$ or MDA $(200 \mu \mathrm{M})$ were} incubated with EGCG $(600 \mu \mathrm{M})$ and $4^{\prime}-\mathrm{NH}_{2}$-EGCG $(600 \mu \mathrm{M})$ separately in phosphate buffer (pH 7.4, final volume $200 \mu \mathrm{L}$ ) at $37^{\circ} \mathrm{C}$. The aerobic incubations were conducted under dark within the incubator shaker (New Brunswick Scientific, Edison, NJ) at $150 \mathrm{rpm}$ and $37^{\circ} \mathrm{C}$ for $6 \mathrm{~h}$ (MGO) and $12 \mathrm{~h}$ (MDA), and the anaerobic incubations were conducted under dark within the anaerobic chamber (Sheldon Manufacturing Inc., Cornelius, OR) at $37^{\circ} \mathrm{C}$ for $6 \mathrm{~h}$ (MGO) and $12 \mathrm{~h}$ (MDA). Every sample was prepared in triplicate. After incubation, the reactions were stopped by adding $2 \mu \mathrm{L}$ of acetic acid. To detect the remaining MGO, the incubation solutions with MGO were derived by adding OPD (10 $\mu \mathrm{L}$ of $100 \mathrm{mM}$ in PBS) based on our previous method [38] and checked by HPLC-DAD. To detect the remaining MDA, the incubation solutions with MDA were derived by adding DNPH ( $4 \mu \mathrm{L}$ of $100 \mathrm{mM}$ in DMSO) at $50{ }^{\circ} \mathrm{C}$ for $1.5 \mathrm{~h}$ and checked by HPLC-DAD. 


\subsubsection{Preparation of the conjugation samples of EGCG and 4'-NH ${ }_{2}$-EGCG with MGO, MDA, and HNE for LC-MS analysis-EGCG $(600 \mu \mathrm{M})$ and 4'-NH ${ }_{2}$-EGCG} $(600 \mu \mathrm{M})$ were incubated with MGO $(200 \mu \mathrm{M})$ for $3 \mathrm{~h}$, MDA $(200 \mu \mathrm{M})$ for $6 \mathrm{~h}$, and 4-HNE $(200 \mu \mathrm{M})$ for $6 \mathrm{~h}$, respectively, in phosphate buffer $\left(\mathrm{pH} \mathrm{7.4)}\right.$ ) at $37^{\circ} \mathrm{C}$. After the reaction, 2 $\mu \mathrm{L}$ of acetic acid was added to all of incubation solutions. Then the conjugation products were checked by LC-MS directly with SRM (selected reaction motoring) mode.

\subsection{HPLC and LC-MS/MS analysis}

2.6.1 Preparative HPLC—Compound purification was performed on a Waters preparative HPLC system (Milford, MA) consisting of a Waters 2535 quarternary graduate pump and Waters 2469 UV/Visible Detector. The column used was a $250 \mathrm{~mm} \times 10 \mathrm{~mm}$ i.d., $5 \mu \mathrm{m}$, Luna $\mathrm{C} 18$ column (Phenomenex, Torrance, CA) with a flow rate of $3 \mathrm{~mL} / \mathrm{min}$ and was eluted with $12 \%$ aqueous acetonitrile.

2.6.2 HPLC-DAD analysis-HPLC-DAD was performed with a Thermo Scientific HPLC system consisting of an Ultimate 3000 RS pump, an Ultimate 3000 RS autosampler, and an Ultimate 3000 DAD. The column used was a $4.6 \mathrm{~mm}$ i.d. $\times 150 \mathrm{~mm}, 5 \mu \mathrm{m}$, Gemini C18 column (Phenomenex, Torrance, $\mathrm{CA}$ ) to analyze the OPD/DNPH derivatives with MGO/MDA and the concentrations of EC, EGC, ECG, and EGCG in green tea with a flow rate of $1.0 \mathrm{~mL} / \mathrm{min}$. For the OPD/DNPH derivatives with MGO/MDA, column elution started with $20 \%$ solvent B (A: $100 \%$ water with $0.1 \%$ formic acid; B: $100 \%$ acetonitrile with $0.1 \%$ formic acid) for 5 mins, followed by a linear increase to $100 \%$ solvent B from 5 to $20 \mathrm{~min}$, and then equilibrated to $20 \% \mathrm{~B}$ from 21 to $25 \mathrm{~min}$ for the next run. For green tea catechins, column elution started with $5 \%$ solvent B for 5 mins, followed by a linear increase to $35 \%$ solvent B from 5 to $25 \mathrm{~min}$, and then a linear increase to $95 \%$ solvent B from 25 to $30 \mathrm{~min}$, keep $95 \%$ solvent B for $3 \mathrm{~min}$, then equilibrated to $5 \% \mathrm{~B}$ for the next run. The detection wavelength was $315 \mathrm{~nm}$ for MGO-OPD derivatives and $305 \mathrm{~nm}$ for MDA-DNPH derivatives, and $280 \mathrm{~nm}$ for green tea catechins. The injection volume of each sample was $80 \mu \mathrm{L}$. The temperature of autosampler was set to $8{ }^{\circ} \mathrm{C}$. For contents of catechins in green tea, four catechins, EC, EGC, ECG, and EGCG were used as standards.

2.6.3 LC-MS Analysis-LC-MS analysis was performed with a Thermo-Finnigan Spectra system consisting of an Ultimate 3000 degasser, an Ultimate 3000 RS pump, an Ultimate 3000 RS autosampler, an Ultimate 3000 RS column compartment, and an LTQ Velos Pro ion trap mass spectrometer (Thermo Electrom) equipped with an electrospray ionization (ESI) interface. Chromatographic separation was performed using a Gemini C18

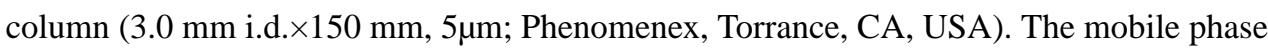
consisted of $5 \%$ aqueous methanol with $0.1 \%$ formic acid (mobile phase A) and $95 \%$ aqueous methanol with $0.1 \%$ formic acid (mobile phase $\mathrm{B}$ ). The gradient elution was performed for $45 \mathrm{~min}$ at a flow rate of $0.3 \mathrm{~mL} / \mathrm{min}$. The gradient was initiated at $0 \% \mathrm{~B}$ and held constant for $10 \mathrm{~min}$, followed by a linear increase to $40 \%$ from 10 to $35 \mathrm{~min}$, to $100 \%$ from 35 to $40 \mathrm{~min}$ and held constant for $5 \mathrm{~min}$. The column was then re-equilibrated with $0 \%$ B for $5 \mathrm{~min}$. The injection volume of each sample was $10 \mu \mathrm{L}$. The LC eluent was introduced into the ESI interface. The negative ion polarity mode was set for the ESI source with the ion spray voltage at approximately $3.6 \mathrm{kV}$. Nitrogen gas was used as the sheath gas 
at a flow rate of 34 arb and the aux gas at a flow rate of 10 arb. Optimized parameters, including temperature $\left(300^{\circ} \mathrm{C}\right)$, voltage of the capillary $(45 \mathrm{~V})$, and voltage of the tube lens offset (120 V), were tuned using authentic EGCG. For MS-MS ${ }^{11}(\mathrm{n}=2-3)$ analysis, collision induced dissociation (CID) was conducted using an isolation width of $1.2 \mathrm{Da}$ and the normalized collision energy of 35 values. The mass range was measured from 50 to 1000 $\mathrm{m} / \mathrm{z}$. Data acquisition and analysis were performed using Xcalibur 2.0 (Thermo Electron; San Jose, CA).

2.6.4 HR-ESI-MS - The HR-ESI-MS of the new aminated metabolite was detected with Thermo Scientific Q Exactive Plus Mass Spectrometer. Calibration was done before detection. The compound was introduced into the HESI interface directly by syringe pump. The negative ion polarity mode was set for the HESI source with the ion spray voltage at 2.5 $\mathrm{kV}$. Nitrogen gas was used as the sheath gas, sweep gas, and the aux gas. Optimized parameters, including sheath gas flow rate, aux gas flow rate, sweep gas flow rate, spray voltage, capillary temperature, S-lens RF level, and aux gas heater temperature were tuned using authentic EGCG. Data acquisition and analysis were performed using Xcalibur (Thermo Electron; San Jose, CA).

\subsection{Statistical Analysis}

All results are presented as means \pm standard deviation. A Student's $t$ test was performed using GraphPad Prism version 5.04. An asterisk (*) means a significant difference comparison with LPS group: $(*) \mathrm{p}<0.05,(* *) \mathrm{p}<0.01,\left({ }^{* *}\right) \mathrm{p}<0.001$, and $(* * *) \mathrm{p}<$ 0.0001 .

\section{Results}

\subsection{Scavenging of toxic reactive species by EGCG in mice}

3.1.1 Amination of EGCG-Tea catechins have been reported to have deodorizing effects on amines and ammonia in vitro [42]. It is unknown whether tea catechins have the capacity to react with ammonia in vivo. In the present study, we searched the aminated EGCG using LC-MS from EGCG treated mouse urinary and fecal samples. A peak at 16.2 min, which showed $\mathrm{m} / \mathrm{z} 456.17$ under the negative mode, was found in both fecal and urinary samples from EGCG treated mice, but not from control mice. The molecular ion of this peak is one Dalton less than EGCG. Its molecular formula was elucidated to be $\mathrm{C}_{22} \mathrm{H}_{19} \mathrm{NO}_{10}$ based on its HR-ESI-MS data at $\mathrm{m} / \mathrm{z} 456.0935$ ([M-H] ${ }^{-}$, calc. 456.0931) which was one oxygen atom less than, but one proton and one nitrogen atom more than EGCG. We predicted that one hydroxyl group in EGCG was replaced with an amine group in this new metabolite.

To determine the structure of this new metabolite, one major aminated-EGCG product was synthesized by reacting EGCG with ammonia (Fig. 1A). Its tandem mass spectrum indicated that the nitrogen was on B-ring. Among the major ions on its $\mathrm{MS}^{2}$ spectrum (Fig. 2A), all ions except the ion of 169 were one Dalton less than those of EGCG. The ions at $m / z 304$ $[\mathrm{M}-152-\mathrm{H}]^{-}$and $286[\mathrm{M}-170-\mathrm{H}]^{-}$from losing the gallate moiety and gallic acid moiety, respectively, and the ion at $\mathrm{m} / \mathrm{z} 169$ (gallic acid) indicated that the possible amine group was 
not on the gallic acid part. Furthermore, on the MS ${ }^{3}$ spectrum of the daughter ion 286 (Fig. $2 \mathrm{~A}$ ), the observation of the ion at $\mathrm{m} / z 160$ which was from the ion at $\mathrm{m} / \mathrm{z} 286$ by losing the A ring [43] and the ion at $\mathrm{m} / \mathrm{z} 125$ from the A-ring indicated that the amine group was not on the A ring. So the amino group was elucidated to be on the B-ring. By comparing its 1DNMR data with those of EGCG, all data were identical except the chemical shift of C-4' which shifted up to $122.1 \mathrm{ppm}$ in synthesized aminated-EGCG from $132.8 \mathrm{ppm}$ in EGCG (Table 1). The observation of the HMBC correlations from H-2' and H-6' to C-4' at $\delta c 122.1$ ppm (Fig. 1A, Table 1) indicated that an amine group was connected to C-4'. Therefore, the structure of the synthesized aminated EGCG was characterized as 4'- $\mathrm{NH}_{2}$-EGCG (2) (Fig. 1A). Its key HMBC correlations were showed in Fig $1 \mathrm{~A}$.

Under selected ion monitoring (SIM) mode of LC-MS, the aminated metabolite of EGCG from in vivo mouse samples showed the same retention time and tandem mass spectrum with those of the synthesized 4'- $\mathrm{NH}_{2}$-EGCG (Fig. 2A). Therefore, this aminated metabolite of EGCG was characterized as 4'-NH 2 -EGCG (2), indicating the EGCG has the capacity to scavenge ammonia in vivo. The aminated EGCG was also detected at even $50 \mathrm{mg} / \mathrm{kg}$ oral dose (Data not shown).

\subsubsection{Conjugation of reactive carbonyl species by EGCG and 4'-NH $\mathrm{NH}_{2}-\mathrm{EGCG}-$} EGCG as the major polyphenol in green tea has been shown to trap MGO in simulated physiological conditions and it's A ring has been identified as the active site to trap MGO [38]. Whether EGCG could scavenge MGO and other RCS in vivo is still unknown. The aminated EGCG metabolite, 4'- $\mathrm{NH}_{2}$-EGCG, retains the A ring structure of EGCG and has the primary amine group that also has the capacity to scavenge RCS. Therefore, we hypothesized that both EGCG and 4'- $\mathrm{NH}_{2}$-EGCG could scavenge RCS in vivo. To test this hypothesis, we searched the formation of EGCG and 4'- $\mathrm{NH}_{2}$-EGCG conjugates of MGO, MDA, and 4-HNE in 24-h urinary and fecal samples collected from mice treated with EGCG and 4'-NH ${ }_{2}-E G C G$ using LC-MS, respectively. The chemical reaction products of EGCG and 4'-NH $\mathrm{NH}_{2}$-EGCG with MGO, MDA, and 4-HNE were used as the standards for the corresponding in vivo EGCG-RCS and 4'-NH ${ }_{2}$-EGCG-RCS metabolites, respectively.

3.1.2.1 Trapping MGO by EGCG and 4'-NH2-EGCG: As shown in Fig. 3A, two peaks with $\mathrm{m} / \mathrm{z} 529[\mathrm{M}-\mathrm{H}]^{-}$in the EGCG-treated mouse urinary and fecal samples showed the same retention times and $\mathrm{MS}^{2}$ spectra with those from the chemical reaction of EGCG with MGO in simulated physiological conditions. In their $\mathrm{MS}^{2}$ spectra, the fragment ion at $\mathrm{m} / \mathrm{z}$ 457 was from losing the MGO moiety $(\mathrm{m} / \mathrm{z} 72)$, the ion at $\mathrm{m} / \mathrm{z} 377$ was from losing the gallic acid moiety $(\mathrm{m} / \mathrm{z} 170)$, and the ion at $m / z 169.0$ was from gallic acid. All of these signals were identical to the mono MGO-EGCG conjugates that we purified from chemical reaction of EGCG and MGO [38]. Therefore, they were identified as the mono MGO-EGCG (Fig. 1B, compound 3).

Since 4'- $\mathrm{NH}_{2}$-EGCG has the same A ring structure as EGCG and the primary amine on the $\mathrm{B}$ ring, we expect to detect the mono MGO-4'-NH 2 -EGCG ( $/ \mathrm{m} / \mathrm{z} 528)$ (Fig. 1B, compound 4) as the A ring conjugate and the mono $N$-MGO-4'- $\mathrm{NH}_{2}$-EGCG ( $\left.\mathrm{m} / \mathrm{z} 510\right)$ (Fig. 1B, compound 5) as the amine conjugate (Fig.1B). Under ESI negative SIM mode, there were one major peak at $11.8 \mathrm{~min}$ and three minor peaks in response to the search of mono 
MGO-4'-NH ${ }_{2}$-EGCG at $\mathrm{m} / \mathrm{z} 528[\mathrm{M}-\mathrm{H}]^{-}$from the chemical reaction sample of 4'- $\mathrm{NH}_{2}{ }^{-}$ EGCG with MGO (Fig. 4A). The peak at $11.8 \mathrm{~min}$ had the daughter ion of $\mathrm{m} / \mathrm{z} 456$ [M-72$\mathrm{H}]^{-}$, which was from the loss of the MGO moiety, the daughter ion of $m / z 358[\mathrm{M}-170-\mathrm{H}]^{-}$, which was from the loss of the gallic acid moiety, and the daughter ion of $m / z 197$ [M-170-161-H $]^{-}$, which was from the loss of the A ring with one MGO moiety. Therefore, this peak was identified as the mono MGO conjugate of 4'- $\mathrm{NH}_{2}$-EGCG on the A ring (Fig. 1B, compound 4). The same peak was detected from the fecal samples collected from EGCG (1) and 4'-NH $-\mathrm{NH}_{2}-\mathrm{EGCG}$ (2) treated mice, respectively (Fig. 4A). They have the same retention time and $\mathrm{MS}^{2}$ spectrum as those of the mono MGO-4'- $\mathrm{NH}_{2}$-EGCG standard from the chemical reaction of 4'- $\mathrm{NH}_{2}$-EGCG with MGO under simulated physiological conditions (Fig. 4A). The three minor peaks from the chemical reaction of 4'- $\mathrm{NH}_{2}$-EGCG with MGO had similar $\mathrm{MS}^{2}$ spectra with that of the peak at $11.8 \mathrm{~min}$ (data not shown), indicating they are the stereoisomers of MGO conjugates at position C-6 or C-8 of 4'-NH $\mathrm{NH}_{2}$-EGCG (Fig. 4A). This is in agreement with our previous observation on the conjugation of MGO with EGCG at the C-6 or C-8 position [38].

Using a similar approach, we detected one major peak at $13.0 \mathrm{~min}$ in response to the search of mono $\mathrm{N}$-MGO-4'-NH $\mathrm{N}_{2}$-EGCG at $\mathrm{m} / \mathrm{z} 510[\mathrm{M}-\mathrm{H}]^{-}$from the chemical reaction sample of 4'-NH 2 -EGCG with MGO (Fig. 4B). This peak was also detected in the fecal samples collected from EGCG (1) treated mice and the urinary and fecal samples collected from 4'$\mathrm{NH}_{2}$-EGCG (2) treated mice (Fig. 4B). They have the same retention time and $\mathrm{MS}^{2}$ spectrum as those of the mono $\mathrm{N}$-MGO-4'-NH $\mathrm{N}_{2}-\mathrm{EGCG}$ standard from the chemical reaction of 4'- $\mathrm{NH}_{2}$-EGCG with MGO under simulated physiological conditions (Fig. 4B). The detection of the MGO conjugates of 4'- $\mathrm{NH}_{2}$-EGCG in EGCG treated mice suggests that the aminated metabolite of EGCG has the capacity to trap MGO and be further metabolized.

3.1.2.2 Trapping MDA by EGCG and 4'-NH 2 -EGCG: As expected, both EGCG and 4'$\mathrm{NH}_{2}$-EGCG could react with MDA to generate corresponding MDA conjugates under simulated physiological conditions (Fig. 5). There were several products generated in the reaction of EGCG and MDA. The major product at 22.4 min was also observed in the fecal samples of EGCG treated mice (Fig. 5A). These two peaks shared the same retention time and tandem mass (Fig. 5A). Both of them had the daughter ions at $\mathrm{m} / \mathrm{z} 359$ and 377 , which were from the typical loss of the gallic acid moiety and the gallate moiety, respectively. We expected that EGCG could trap MDA following the same mechanism of trapping MGO. Therefore, we tentatively identified the MDA conjugate of EGCG as shown in Fig. 1B (compound 6). Even though the MDA conjugate of EGCG has the same molecular weight with the MGO conjugate of EGCG, they have different retention times and tandem mass fragments (Fig. 3A and 5A).

One major product at 17.8 min was observed in response to the search of A ring MDA conjugate of 4'-NH $\mathrm{NHGCG}_{2}$, mono MDA-4'-NH ${ }_{2}$-EGCG at $\mathrm{m} / z 528$ [M-H] ${ }^{-}$(Fig. 1B,

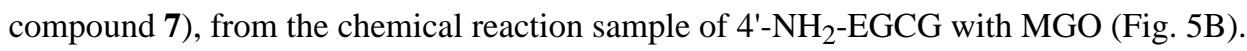
This peak was also detected from fecal samples collected from EGCG (I) treated mice, and urinary and fecal samples from 4'--NH 2 -EGCG (2) treated mice (Fig. 5B). They all have the fragment ion at $m / z 456$ by losing one MDA moiety. 
In the search of the mono $N$-MDA-4'-NH ${ }_{2}$-EGCG at $m / z 510[\mathrm{M}-\mathrm{H}]^{-}$(Fig. 1B, compound 8), the MDA conjugate of the amine group of 4'- $\mathrm{NH}_{2}-\mathrm{EGCG}$, one major product was observed at $20.6 \mathrm{~min}$ from the chemical reaction sample of 4'- $\mathrm{NH}_{2}-\mathrm{EGCG}$ with MGO (Fig. 5C). This peak was detected in the urinary and fecal samples collected from 4'- $\mathrm{NH}_{2}-\mathrm{EGCG}$ (2) treated mice. They all have the same retention time and tandem mass spectrum with the major daughter ion at $\mathrm{m} / \mathrm{z} 466$ from losing one $\mathrm{CO}_{2}$ moiety, at $\mathrm{m} / \mathrm{z} 358$ and 340 from the typical loss of one gallic acid moiety and one gallate moiety, respectively, at $\mathrm{m} / z 214$ from the loss of A-ring ( $\mathrm{m} / \mathrm{z} 126)$ and the gallate moiety (Fig. 5C).

3.1.2.3 Trapping HNE by EGCG and 4'-NH -EGCG: It has been reported that EGCG quenched 4-HNE to generate mono HNE-EGCG (Fig. 1B, compound 9) [40]. In the current study, after incubation of EGCG with 4-HNE, one peak with $\mathrm{m} / \mathrm{z} 595[\mathrm{M}-\mathrm{H}]^{-}$appeared at $18.5 \mathrm{~min}$ in the search of mono HNE-EGCG (Fig. 5D). This peak was also detected in the fecal samples collected from EGCG (1) treated mice. Both peaks had the same retention time and tandem mass spectrum with $\mathrm{m} / \mathrm{z} 443[\mathrm{M}-152-\mathrm{H}]^{-}$and $425[\mathrm{M}-170-\mathrm{H}]^{-}$, the typical loss of one gallate moiety and one gallic acid moiety, respectively, which is consistent with what reported in the literature [40]. There was a shoulder peak of this major peak which showed the identical $\mathrm{m} / \mathrm{z}$ and $\mathrm{MS}^{2}$ data to the major peak (data not shown). These two peaks with the same molecular weights were proposed due to the stereoisomers at hemiacetal carbon. Therefore, we proposed the structure of the conjugated products of EGCG with 4HNE as compound 9 in Fig. 1B.

In the search of the 4-HNE conjugates of 4'-NH $\mathrm{N}_{2}$-EGCG, we could detect the conjugate of HNE with the amine group of $4{ }^{\prime}-\mathrm{NH}_{2}-\mathrm{EGCG}\left(\mathrm{m} / z 576[\mathrm{M}-\mathrm{H}]^{-}\right)$, not the conjugate on the Aring $\left(\mathrm{m} / \mathrm{z} 594[\mathrm{M}-\mathrm{H}]^{-}\right)$from the chemical reaction samples of 4'-NH $2-\mathrm{EGCG}$ and 4-HNE and the 4'-NH ${ }_{2}$-EGCG (2) treated mouse fecal samples. As shown in Fig. 5E, only one peak with $\mathrm{m} / \mathrm{z} 576[\mathrm{M}-\mathrm{H}]^{-}$appeared at $29.6 \mathrm{~min}$ in the search of mono $\mathrm{N}$-HNE-4'-NH $\mathrm{N}_{2}$-EGCG (Fig. 5E). Its $\mathrm{MS}^{2}$ spectrum had the daughter ions at $\mathrm{m} / \mathrm{z} 424$ [M-152-H] $]^{-}$from the typical loss of gallate moiety and at $\mathrm{m} / \mathrm{z} 438[\mathrm{M}-138-\mathrm{H}]^{-}$from the loss of the A-ring which confirmed that 4-HNE was connected to the amine group of B-ring, but not A-ring.

\subsection{Scavenging of toxic reactive species by EGCG in humans}

Our mouse data clearly demonstrated that EGCG could scavenge toxic reactive species such as ammonia, MGO, MDA, and 4-HNE. To demonstrate whether this occurs in humans, we collected human urinary and fecal samples after drinking green tea (4 cups per day and each cup of tea has $74.6 \mathrm{mg}$ EGCG, $11.6 \mathrm{mg}$ EC, $46.9 \mathrm{mg}$ EGC, and $15.7 \mathrm{mg} \mathrm{ECG).} \mathrm{Using}$

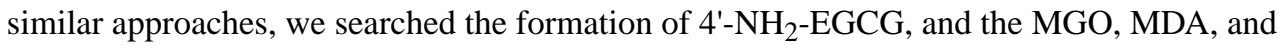

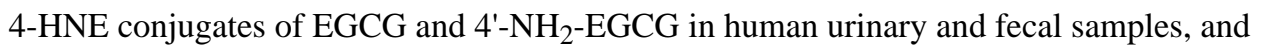
were able to identify 4 '- $\mathrm{NH}_{2}$-EGCG and mono MGO-EGCG from human samples. As shown in Fig. 2B, 4'-NH $-\mathrm{NH}_{2}$-EGCG was detected from both the urinary and fecal samples collected from the two subjects after drinking commercial green tea, but not from the baseline samples. The MGO conjugated metabolites of EGCG, mono MGO-EGCG, were detected from the fecal samples of both subjects, especially in subject 2 (Fig. 3B). 


\subsection{The factors influencing the scavenging capacity of EGGC}

3.3.1 Gut microbiota-The production of ammonia [15, 16] and MGO [37, 44] in intestine was closely related with gut microbiota. The contribution of gut microbiota to the formation of EGCG conjugates with toxic reactive species has never been studies. We compared the formation of $\mathrm{NH}_{2}$-EGCG (2), MGO-EGCG (3), MGO-NH ${ }_{2}$-EGCG (4), $\mathrm{N}$ MGO-NH 2 -EGCG (5), MDA-EGCG (6), $N$-MDA-NH 2 -EGCG (8), and HNE-EGCG (9) in GF mice and SPF mice. As shown in Fig. 6A, the levels of $\mathrm{NH}_{2}$-EGCG (2), MGO-NH ${ }_{2}^{-}$ EGCG (4), MDA-EGCG (6), and HNE-EGCG (9) were significantly higher (more than 2fold) in SPF mice than in GF mice ( $p<0.05$ ). Even though it is not statistically significant, the levels of MGO-EGCG (3), $N$-MGO-NH 2 -EGCG (5), and $N$-MDA-NH ${ }_{2}$-EGCG (8) are also higher in SPF mice than in GF mice (Fig. 6A). Our results clearly demonstrated that gut microbiota play an important role on the trapping of toxic reactive species by EGCG.

3.3.2 Oxygen-Under in vitro conditions, EGCG has the capacity to trap different reactive species. The oxygen level is much lower in in vivo than in in vitro conditions. We hypothesized that these reactions do not require the oxidation of EGCG to its quinone and can directly occur under both aerobic and anaerobic conditions. To test this hypothesis, we compared the scavenging capacity of EGCG (1) and 4'-NH 2 -EGCG (2) to MGO and MDA in simulated physiological system under aerobic and anaerobic conditions to compare the oxygen effect to the conjugation reaction. The results in Fig. 6B showed that with or without oxygen, both compounds could significantly scavenge MGO after incubation for $6 \mathrm{~h}$. Under aerobic conditions, 4'- $\mathrm{NH}_{2}$-EGCG had a better trapping capacity of MGO than EGCG, which was not observed under anaerobic conditions. We observed a similar phenomenon for trapping of MDA by both compounds under aerobic conditions and anaerobic conditions (Fig. 6C). In both cases, oxygen is not essential for the trapping of reactive species by EGCG and 4'- $\mathrm{NH}_{2}$-EGCG, but may slightly accelerate the trapping capacity of both compounds. Since the aldehyde group in MDA is much less reactive than the one in MGO, we observed a slower reaction of EGCG and 4'- $\mathrm{NH}_{2}$-EGCG with MDA than with MGO, and both compounds trapped less MDA than MGO.

\subsection{Aminated EGCG metabolite retains the bioactivities of EGCG}

\subsubsection{Growth inhibitory effect of EGCG and 4'- $\mathrm{NH}_{2}$-EGCG on human colon} cancer cells-Since EGCG was reported to be the most effective cancer chemopreventive polyphenol in green tea $[45,46]$ and hydroxyl and amine groups are bioisosteres, we

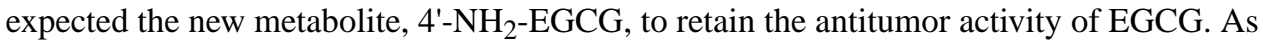
shown in Fig. 7A, both 4'-NH ${ }_{2}$-EGCG and EGCG could significantly inhibit the growth of HCT-116 and HT-29 human colon cancer cells, and the $\mathrm{IC}_{50}$ s of 4'-NH $\mathrm{NH}_{2}$-EGCG against the growth of HCT-116 and HT-29 cells were $67.58 \mu \mathrm{M}$ and $73.43 \mu \mathrm{M}$, which were slightly higher than those of EGCG ( $43.88 \mu \mathrm{M}$ for HCT-116 cells and $59.69 \mu \mathrm{M}$ for HT-29 cells), respectively.

\subsubsection{Inhibitory effects of EGCG and 4'- $\mathrm{NH}_{2}$-EGCG on LPS-induced nitrite production and iNOS expression in RAW 264.7 macrophages-To evaluate the} anti-inflammatory effects of EGCG and its metabolite 4'- $\mathrm{NH}_{2}$-EGCG, we tested their effect on nitrite production and inducible No synthase (iNOS) expression in LPS-activated 
macrophages. As shown in Fig. 7B, both EGCG and 4'-NH 2 -EGCG inhibited NO production at three different doses $(12.5,25$, and $50 \mu \mathrm{M})$ compared with LPS treatment alone. Both compounds inhibited more than $50 \%$ of NO production at $12.5 \mu \mathrm{M}$, and they had the similar inhibitive effects of NO production at $50 \mu \mathrm{M}$. Moreover, we investigated whether EGCG and 4'-NH ${ }_{2}$-EGCG might affect the expression of iNOS, which mediates NO production and is one of the inflammatory factors correlated with LPS stimulation. As shown in Fig. 7C, treatments of EGCG and 4'-NH $\mathrm{NH}_{2}$-EGCG suppressed iNOS expression significantly in a dosedependent manner when compared with LPS treatment alone, which were consistent with the reductions in total $\mathrm{NO}$ in culture media.

\section{Discussion}

Ammonia is a by-product of cellular metabolism, and is converted to urea in the liver and excreted in urine [15]. In the setting of chronic/acute liver failure the level of ammonia in the circulation system will increase 10-50 times comparing to the levels in a healthy body due to multi-organ dysfunction in which ammonia acts as a neurotoxin [15]. Reducing ammonia is one major therapeutic regimen for hepatic encephalopathy or hyperammonemia $[15,16]$. In this study, we discovered that EGCG, the major catechin in green tea, could efficiently react with ammonia to generate the aminated metabolite of EGCG in mice and humans. More interestingly, the aminated metabolite of EGCG retains the bioactivity of EGCG by showing similar trapping effects of RCS, growth inhibitory effects on cancer cells, and antiinflammatory effects in macrophage cells. It has been reported that $300 \mathrm{mg}$ of tea catechins a day for 6 weeks significantly decreased the fecal concentrations of ammonia in elderlies [47]. Based on our results, it is possible that this observation is due to the trapping of ammonia by tea catechins especially EGCG, which indicates EGCG has the potential to be used to prevent ammonia-related diseases. However, this needs to be proved experimentally, especially on how much of ammonia can be trapped by EGCG in human.

Recently, Haigis et al. [48] reported that ammonia is not merely a toxic waste product, but is recycled into central amino acid metabolism to maximize nitrogen utilization to support the growth of breast cancer cells. In mice, they found that ammonia accumulated in the tumor microenvironment and was used directly to generate amino acids through glutamate dehydrogenase activity to support breast cancer biomass. It is known that EGCG could inhibit the growth of various types of cancer cells. It is an interesting topic to further study whether EGCG could inhibit the growth of cancer cells by blocking the recycling of ammonia.

The most abundant RCS are produced from oxidation of carbohydrates, lipids, and amino acids, and most of them are considered the primary waste products or toxic endogenous products. EGCG has been reported to scavenge RCS in in vitro systems. In this study, we provided the first in vivo evidence that EGCG has the capacity to trap MGO, MDA, and 4$\mathrm{HNE}$ and form RCS conjugates on A-ring. Interestingly, the aminated metabolite has two functional groups, the A-ring and the primary amine group, to trap RCS. Our results demonstrated that both the A-ring and the primary amine group of the aminated metabolite of EGCG could react with RCS to generate the corresponding RCS conjugates. Besides 
trapping MGO, MDA, and 4-HNE, the conjugates of glyoxal (GO) and acrolein (ACR) with EGCG and 4'- $\mathrm{NH}_{2}$-EGCG were also detected in mice but in trace amount (data not shown).

It has been reported that gut microbiota plays an important role on the formation of ammonia and RCS $[15,16,37,44]$. To verify the role of gut microbiota on the formation of the aminated metabolite of EGCG, and the RCS conjugates of EGCG and its aminated metabolites, we compared the levels of these metabolites in EGCG treated GF mice and SPF mice. Our results clearly demonstrated that gut microbiota facilitate the formation of the aminated metabolite of EGCG and the RCS conjugates of EGCG and its aminated metabolites. Although the possible mechanism could be very complex, our results confirmed that gut microbiota closely related to amination and conjugation of EGCG with reactive species including ammonia, MGO, MDA, and HNE. It is possible that EGCG could be oxidized by gut microbiota to generate the EGCG quinone, which will rapidly react with ammonia to produce the aminated metabolite of EGCG (Fig. 8). Then, both EGCG and its aminated metabolite could scavenge RCS in the gut. The detection of the aminated metabolite and the RCS conjugates of EGCG in GF mice suggests that the host also contributes to the oxidation of EGCG and then the trapping of RCS. Therefore, both host and microbiota participate in the detoxication process of reactive metabolites.

This study provides in vivo evidences that EGCG has the capacity to scavenge toxic reactive metabolic wastes. Our result that oxygen is not essential for the trapping of reactive species by EGCG and 4'- $\mathrm{NH}_{2}$-EGCG suggests that EGCG and its aminated metabolite could scavenge RCS in the GI track and in the circulation system. It is worthwhile to determine how much of RCS could be trapped by EGCG and its aminated metabolite in future studies. In addition, it is also critical to know whether the RCS conjugates of EGCG and aminated EGCG remain bioactive. In this study, we provided the in vitro evidence that aminated EGCG retains the growth inhibitory effects of EGCG in human colon cancer cells and the anti-inflammatory effects of EGCG in macrophages. Further studies are needed to demonstrate the in vivo efficacy of aminated EGCG, and the RCS conjugates of EGCG and its aminated metabolite.

Many other flavonoids and phenolic compounds have been reported to scavenge RCS in in vitro system [49-51]. It is very likely they could act like EGCG to scavenge RCS in human. In addition, we have reported the additive effects of trapping MGO between flavonoids and flavonoids with other phenolic compounds in in vitro system [49, 52]. For habitual tea drinkers, it is possible to intake enough EGCG to scavenge significant amount of ammonia and RCS. In most of the cases, the daily intake of individual flavonoids and phenolic compounds may not be very high. However, the total polyphenol intake could reach $1 \mathrm{~g} /$ day [53], which will be high enough to keep the daily levels of the toxic metabolic wastes low and therefore prevent the development of chronic diseases. This finding will open a new window for us to understand the underlying mechanisms that drinking tea and eating polyphenol-rich foods could prevent the development of chronic diseases and lead to the promotion of healthy foods to the general publics. It might be difficult to demonstrate such effects in subjects living a healthy life style. However, it is possible to design studies in subjects who eat high sugar and high fat diet or smoke cigarettes. 


\section{Supplementary Material}

Refer to Web version on PubMed Central for supplementary material.

\section{Acknowledgments}

Funding

We gratefully acknowledge financial support from NIH R01 grant AT008623 to S. Sang and C. Jobin.

\section{REFERENCES}

1. Sang S, et al., The chemistry and biotransformation of tea constituents. Pharmacological Research, 2011 64(2): p. 87-99. [PubMed: 21371557]

2. Sukhthankar M, et al., A Green Tea Component Suppresses Posttranslational Expression of Basic Fibroblast Growth Factor in Colorectal Cancer. Gastroenterology, 2008 134(7): p. 1972-1980. [PubMed: 18549879]

3. Lu Y-P, et al., Topical applications of caffeine or (-)-epigallocatechin gallate (EGCG) inhibit carcinogenesis and selectively increase apoptosis in UVB-induced skin tumors in mice. Proceedings of the National Academy of Sciences, 2002 99(19): p. 12455-12460.

4. Siddiqui IA, et al., Green tea polyphenol EGCG sensitizes human prostate carcinoma LNCaP cells to TRAIL-mediated apoptosis and synergistically inhibits biomarkers associated with angiogenesis and metastasis. Oncogene, 2008 27(14): p. 2055-63. [PubMed: 17998943]

5. Baliga MS, Meleth S, and Katiyar SK, Growth inhibitory and antimetastatic effect of green tea polyphenols on metastasis-specific mouse mammary carcinoma 4T1 cells in vitro and in vivo systems. Clin Cancer Res, 2005 11(5): p. 1918-27. [PubMed: 15756018]

6. Khan $\mathrm{N}$ and Mukhtar H, Cancer and metastasis: prevention and treatment by green tea. Cancer metastasis reviews, 2010 29(3): p. 435-445. [PubMed: 20714789]

7. Sampath C, et al., Green tea epigallocatechin 3-gallate alleviates hyperglycemia and reduces advanced glycation end products via nrf2 pathway in mice with high fat diet-induced obesity. Biomed Pharmacother, 2017 87: p. 73-81. [PubMed: 28040599]

8. Suzuki T, et al., Beneficial Effects of Tea and the Green Tea Catechin Epigallocatechin-3-gallate on Obesity. Molecules, 2016 21(10).

9. Wolfram S, et al., Epigallocatechin Gallate Supplementation Alleviates Diabetes in Rodents. The Journal of Nutrition, 2006 136(10): p. 2512-2518. [PubMed: 16988119]

10. Singh NA, Mandal AKA, and Khan ZA, Potential neuroprotective properties of epigallocatechin-3gallate (EGCG). Nutrition Journal, 2016 15: p. 60. [PubMed: 27268025]

11. Gu H-F, et al., Epigallocatechin-3-Gallate Attenuates Impairment of Learning and Memory in Chronic Unpredictable Mild Stress-Treated Rats by Restoring Hippocampal Autophagic Flux. PLoS One, 2014 9(11): p. e112683. [PubMed: 25393306]

12. Cascella M, et al., The efficacy of Epigallocatechin-3-gallate (green tea) in the treatment of Alzheimer's disease: an overview of pre-clinical studies and translational perspectives in clinical practice. Infectious Agents and Cancer, 2017 12: p. 36. [PubMed: 28642806]

13. Khurana S, et al., Polyphenols: benefits to the cardiovascular system in health and in aging. Nutrients, 2013 5(10): p. 3779-827. [PubMed: 24077237]

14. Eng QY, Thanikachalam PV, and Ramamurthy S, Molecular understanding of Epigallocatechin gallate (EGCG) in cardiovascular and metabolic diseases. J Ethnopharmacol, 2018 210: p. 296310. [PubMed: 28864169]

15. Sturgeon JP and Shawcross DL, Recent insights into the pathogenesis of hepatic encephalopathy and treatments. Expert Rev Gastroenterol Hepatol, 2014 8(1): p. 83-100. [PubMed: 24236755]

16. Matoori S and Leroux J-C, Recent advances in the treatment of hyperammonemia. Advanced Drug Delivery Reviews, 2015 90: p. 55-68. [PubMed: 25895618]

17. Rabbani N, Xue M, and Thornalley PJ, Dicarbonyls and glyoxalase in disease mechanisms and clinical therapeutics. Glycoconj J, 2016 33(4): p. 513-25. [PubMed: 27406712] 
18. Odani $\mathrm{H}$ et al., Increase in three alpha,beta-dicarbonyl compound levels in human uremic plasma: specific in vivo determination of intermediates in advanced Maillard reaction. Biochem Biophys Res Commun, 1999 256(1): p. 89-93. [PubMed: 10066428]

19. Lapolla A, et al. Glyoxal and methylglyoxal levels in diabetic patients: quantitative determination by a new GC/MS method. Clin Chem Lab Med, 2003 41(9): p. 1166-73. [PubMed: 14598866]

20. Matsuura K, et al., 3-Deoxyglucosone reductase in dog adrenal glands. Identification as aldose reductase. Biol Pharm Bull, 1995 18(12): p. 1765-7. [PubMed: 8787803]

21. Toth AE, et al., Compounds blocking methylglyoxal-induced protein modification and brain endothelial injury. Arch Med Res, 2014 45(8): p. 753-64. [PubMed: 25446614]

22. Tajes M, et al., Methylglyoxal reduces mitochondrial potential and activates Bax and caspase- 3 in neurons: Implications for Alzheimer's disease. Neurosci Lett, 2014 580: p. 78-82. [PubMed: 25102327]

23. Angeloni C, Zambonin L, and Hrelia S, Role of methylglyoxal in Alzheimer's disease. Biomed Res Int, 2014 2014: p. 238485. [PubMed: 24734229]

24. Srikanth V, et al., Methylglyoxal, cognitive function and cerebral atrophy in older people. J Gerontol A Biol Sci Med Sci, 2013 68(1): p. 68-73. [PubMed: 22496536]

25. Beeri MS, et al., Serum concentration of an inflammatory glycotoxin, methylglyoxal, is associated with increased cognitive decline in elderly individuals. Mech Ageing Dev, 2011 132(11-12): p. 583-7. [PubMed: 22079406]

26. Ahmed N, et al., Protein glycation, oxidation and nitration adduct residues and free adducts of cerebrospinal fluid in Alzheimer's disease and link to cognitive impairment. J Neurochem, 2005 92(2): p. 255-63. [PubMed: 15663474]

27. Nemet I, Varga-Defterdarovic L, and Turk Z, Methylglyoxal in food and living organisms. Mol Nutr Food Res, 2006 50(12): p. 1105-17. [PubMed: 17103372]

28. Degen J, Hellwig M, and Henle T, 1,2-dicarbonyl compounds in commonly consumed foods. J Agric Food Chem, 2012 60(28): p. 7071-9. [PubMed: 22724891]

29. Hellwig M, Degen J, and Henle T, 3-deoxygalactosone, a "new" 1,2-dicarbonyl compound in milk products. J Agric Food Chem, 2010 58(19): p. 10752-60. [PubMed: 20822095]

30. Zhu Q, et al., Natural Polyphenols as Direct Trapping Agents of Lipid Peroxidation-Derived Acrolein and 4-Hydroxy-trans-2-nonenal. Chemical Research in Toxicology, 2009 22(10): p. 1721-1727. [PubMed: 19743801]

31. Mali VR and Palaniyandi SS, Regulation and therapeutic strategies of 4-hydroxy-2-nonenal metabolism in heart disease. Free Radic Res, 2014 48(3): p. 251-63. [PubMed: 24237196]

32. Zarkovic N, 4-hydroxynonenal as a bioactive marker of pathophysiological processes. Mol Aspects Med, 2003 24(4-5): p. 281-91. [PubMed: 12893006]

33. Khoubnasabjafari M, Ansarin K, and Jouyban A, Reliability of malondialdehyde as a biomarker of oxidative stress in psychological disorders. BioImpacts : BI, 2015 5(3): p. 123-127. [PubMed: 26457249]

34. Sonnenburg JL and Bäckhed F, Diet-microbiota interactions as moderators of human metabolism. Nature, 2016 535(7610): p. 56-64. [PubMed: 27383980]

35. Nicholson JK, et al., Host-Gut Microbiota Metabolic Interactions. Science, 2012 336(6086): p. 1262-1267. [PubMed: 22674330]

36. Koppel N, Rekdal VM, and Balskus EP, Chemical transformation of xenobiotics by the human gut microbiota. Science (New York, N.Y.), 2017 356(6344): p. eaag2770.

37. Ferguson GP, et al., Methylglyoxal production in bacteria: suicide or survival? Archives of Microbiology, 1998 170(4): p. 209-218. [PubMed: 9732434]

38. Lambert JD, Sang S, and Yang CS, Biotransformation of green tea polyphenols and the biological activities of those metabolites. Mol Pharm, 2007 4(6): p. 819-25. [PubMed: 17963356]

39. Lo CY, et al., Trapping reactions of reactive carbonyl species with tea polyphenols in simulated physiological conditions. Mol Nutr Food Res, 2006 50(12): p. 1118-28. [PubMed: 17103374]

40. Beretta G, et al., Quenching of $\alpha, \beta$-unsaturated aldehydes by green tea polyphenols: HPLC-ESIMS/MS studies. Journal of Pharmaceutical and Biomedical Analysis, 2008 48(3): p. 606-611. [PubMed: 18619756] 
41. Chen H, et al., Metabolism of [6]-shogaol in mice and in cancer cells. Drug Metab Dispos, 2012 40(4): p. 742-53. [PubMed: 22246389]

42. Kida K, et al., Deodorizing effects of tea catechins on amines and ammonia. Biosci Biotechnol Biochem, 2002 66(2): p. 373-7. [PubMed: 11999411]

43. Sang S, et al., Human urinary metabolite profile of tea polyphenols analyzed by liquid chromatography/electrospray ionization tandem mass spectrometry with data-dependent acquisition. Rapid Commun Mass Spectrom, 2008 22(10): p. 1567-78. [PubMed: 18433082]

44. Baskaran S, Rajan DP, and Balasubramanian KA, Formation of methylglyoxal by bacteria isolated from human faeces. J Med Microbiol, 1989 28(3): p. 211-5. [PubMed: 2926792]

45. Wubetu GY, et al., Epigallocatechin gallate hinders human hepatoma and colon cancer sphere formation. J Gastroenterol Hepatol, 2016 31(1): p. 256-64. [PubMed: 26241688]

46. Du G-J, et al., Epigallocatechin Gallate (EGCG) Is the Most Effective Cancer Chemopreventive Polyphenol in Green Tea. Nutrients, 2012 4(11): p. 1679-1691. [PubMed: 23201840]

47. Goto K, et al., The effects of tea catechins on fecal conditions of elderly residents in a long-term care facility. J Nutr Sci Vitaminol (Tokyo), 1999 45(1): p. 135-41. [PubMed: 10360248]

48. Spinelli JB, et al., Metabolic recycling of ammonia via glutamate dehydrogenase supports breast cancer biomass. Science, 2017.

49. Shao X, et al., Essential Structural Requirements and Additive Effects for Flavonoids to Scavenge Methylglyoxal. J Agric Food Chem, 2014 62(14): p. 3202-3210. [PubMed: 24689984]

50. Zhu Y, et al., Bioactive ginger constituents alleviate protein glycation by trapping methylglyoxal. Chem Res Toxicol, 2015 28(9): p. 1842-9. [PubMed: 26247545]

51. Lv L, et al., Stilbene glucoside from Polygonum multiflorum Thunb.: a novel natural inhibitor of advanced glycation end product formation by trapping of methylglyoxal. J Agric Food Chem, 2010 58(4): p. 2239-45. [PubMed: 20104848]

52. Huang Q, et al., Additive Capacity of [6]-Shogaol and Epicatechin To Trap Methylglyoxal. J Agric Food Chem, 2017 65(38): p. 8356-8362. [PubMed: 28866888]

53. Scalbert A and Williamson G, Dietary Intake and Bioavailability of Polyphenols. The Journal of Nutrition, 2000 130(8): p. 2073S-2085S. [PubMed: 10917926] 


\section{Highlights}

1. EGCG could trap ammonia in mice and in humans to form aminated metabolite

2. EGCG could scavenge toxic reactive metabolic wastes in mice and in humans

3. Gut microbiota facilitates the formation of the novel metabolites

4. Aminated metabolite retains the relative biological activities of EGCG 
A<smiles>CC(C)CC1Oc2cc(O)cc(O)c2CC1OC(=O)c1cc(O)c(O)c(O)c1</smiles>

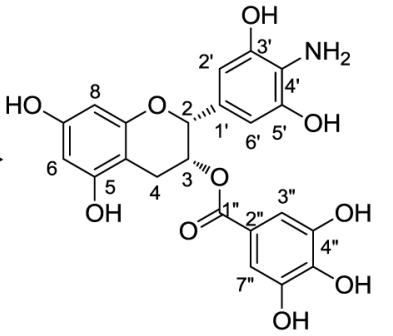

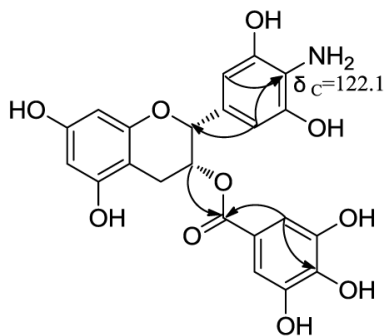
EGCG (1)

4'-NH 2 -EGCG (2)

B<smiles>[B]OC(=O)c1c(O)cc(O)c2c1O[C@H](c1cc(O)c(O)c(O)c1)C(OC(=O)c1cc(O)c(O)c(O)c1)C2</smiles><smiles>CC(=O)C(O)c1c(O)cc(O)c2c1O[C@H](c1cc(O)c(N)c(O)c1)C[C@H](OC(=O)c1cc(O)c(O)c(O)c1)C2</smiles><smiles>CC(=O)C=Nc1c(O)cc([C@@H]2Oc3cc(O)cc(O)c3C[C@H]2OC(=O)c2cc(O)c(O)c(O)c2)cc1O</smiles>

MGO-EGCG (3)

MGO-NH$H_{2}$-EGCG (4)

$\mathrm{N}$-MGO-NH - -EGCG (5)<smiles>O=CCC(O)c1c(O)cc(O)c2c1O[C@H](c1cc(O)c(O)c(O)c1)C[C@H](OC(=O)c1cc(O)c(O)c(O)c1)C2</smiles><smiles>CNC(=O)C(C)(C)NC(=O)O</smiles>

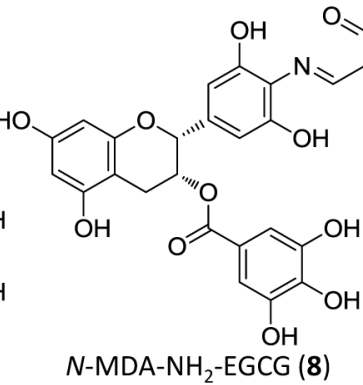<smiles>CCCC/C=C1\C[C@H](O)Oc2cc(O)c3c(c21)O[C@H](c1cc(O)c(O)c(O)c1)C[C@@H](OC(=O)c1cc(O)c(O)c(O)c1)C3</smiles>

MDA-EGCG (6)

Figure 1.

(A) The structures of EGCG (1) and 4'-NH 2 -EGCG (2), the synthetic conditions, and the key HMBC correlations of 4'-NH $\mathrm{NH}_{2}$-EGCG. (B) The proposed structures of the methylglyoxal (MGO), malondialdehyde (MDA), and trans-4-hydroxy-2-nonenal (4-HNE) conjugated metabolites of EGCG and 4'-NH ${ }_{2}$-EGCG. 

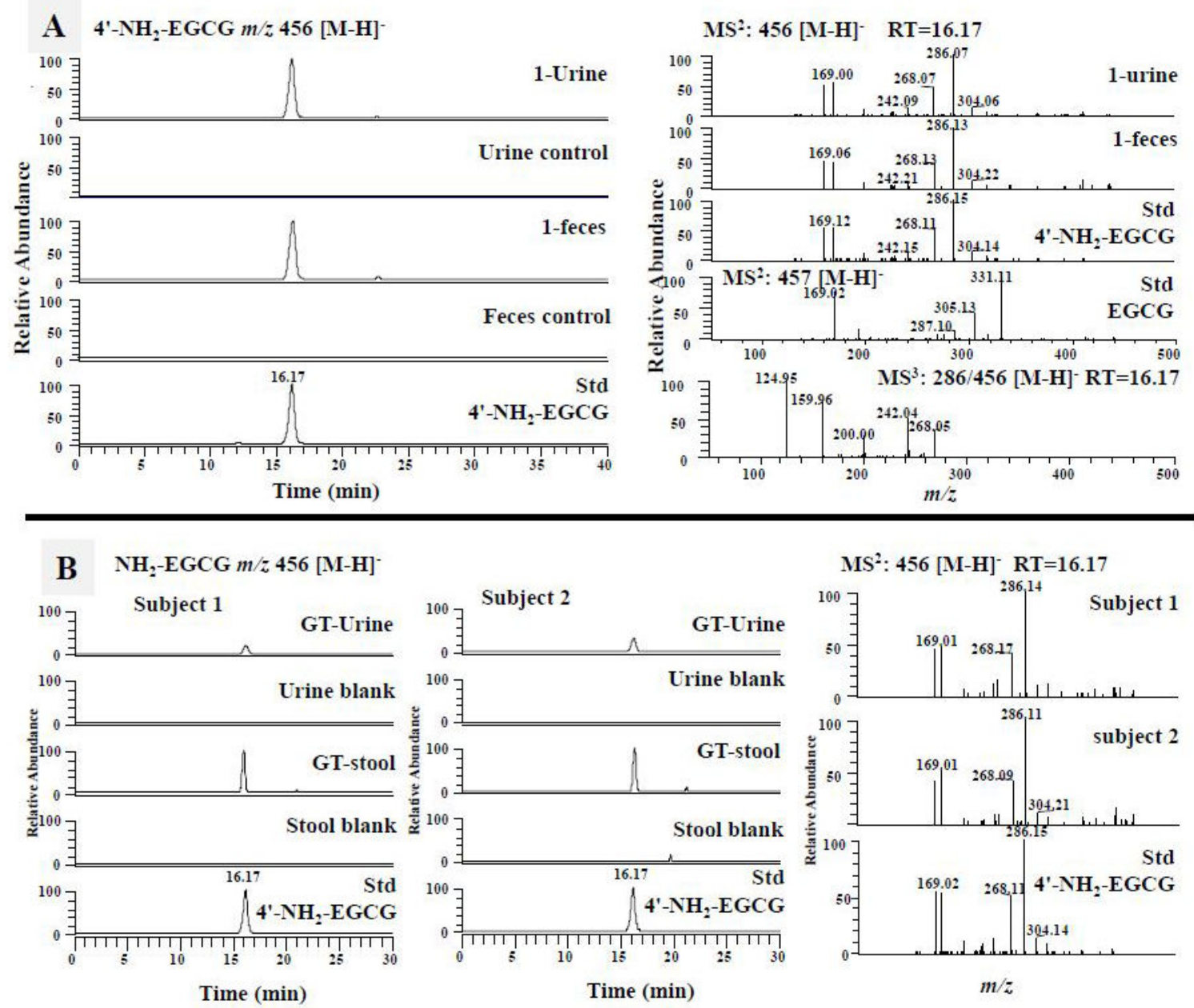

Figure 2.

The formation of the aminated metabolite of EGCG, 4'- $\mathrm{NH}_{2}-\mathrm{EGCG}$, in mice and humans.

(A) The LC chromatograms under selected ion monitoring (SIM) mode of 4'-NH2-EGCG of mouse fecal and urinary samples collected from EGCG $(\mathbf{1})$ treated mice and vehicle treated mice (Control), and the synthetic standard of 4'- $\mathrm{NH}_{2}$-EGCG, the ESI-MS ${ }^{2}$ (negative ion) spectra of the ion $m / z 456[\mathrm{M}-\mathrm{H}]^{-}$from EGCG-treated mouse samples, synthetic standard of 4'-NH ${ }_{2}$-EGCG, the ESI-MS ${ }^{2}$ (negative ion) spectrum of authentic EGCG standard ( $\mathrm{m} / \mathrm{z} 457$ $[\mathrm{M}-\mathrm{H}]^{-}$), and the ESI-MS ${ }^{3}$ (negative ion) spectrum of the fragment ion $\mathrm{m} / \mathrm{z} 287 / 456$. (B) The LC chromatograms under SIM mode of 4'- $\mathrm{NH}_{2}$-EGCG of human urinary and stool samples collected from two human subjects before and after drinking green tea, and the synthetic standard of 4'- $\mathrm{NH}_{2}$-EGCG, the representative ESI-MS ${ }^{2}$ (negative ion) spectra of the ion $\mathrm{m} / \mathrm{z} 456[\mathrm{M}-\mathrm{H}]^{-}$from the two tea drinkers, and the synthetic standard of $4^{\prime}-\mathrm{NH}_{2}-$ EGCG 

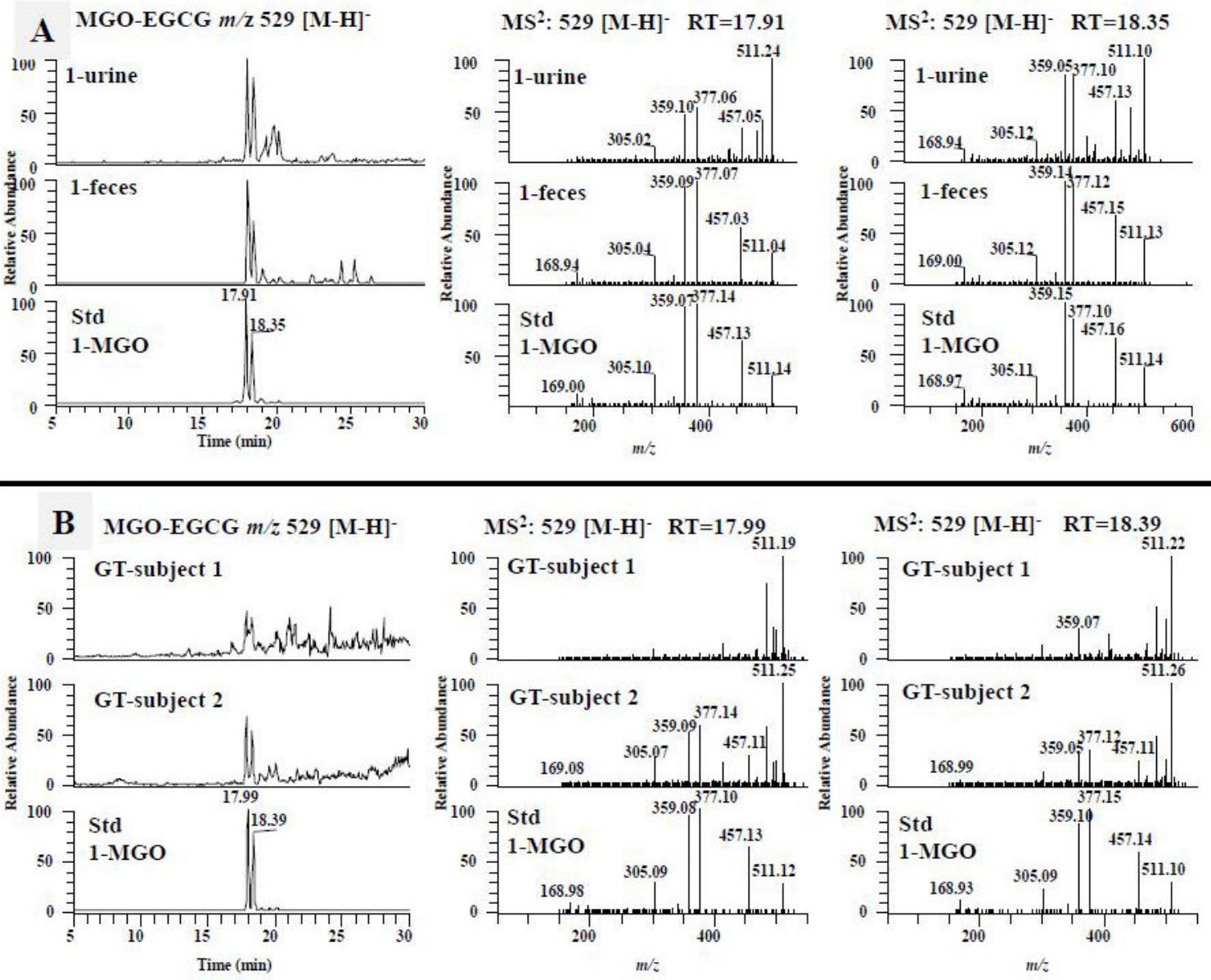

Figure 3.

The formation of the methylglyoxal (MGO) conjugated metabolites of EGCG in mice and humans. (A) The LC chromatograms and the ESI-MS ${ }^{2}$ spectra of mono MGO-EGCG $(\mathrm{m} / \mathrm{z}$ $529[\mathrm{M}-\mathrm{H}]^{-}$) of mouse fecal and urinary samples collected from EGCG (1) treated mice, and the sample collected from chemical incubation of EGCG (1) with MGO in phosphate buffer (pH 7.4) at $37^{\circ} \mathrm{C}$ for $3 \mathrm{~h}$. (B) The LC chromatograms and the ESI-MS ${ }^{2}$ spectra of mono MGO-EGCG $\left(\mathrm{m} / \mathrm{z} 529[\mathrm{M}-\mathrm{H}]^{-}\right)$from human fecal samples collected from 2 human subjects after drinking green tea. 

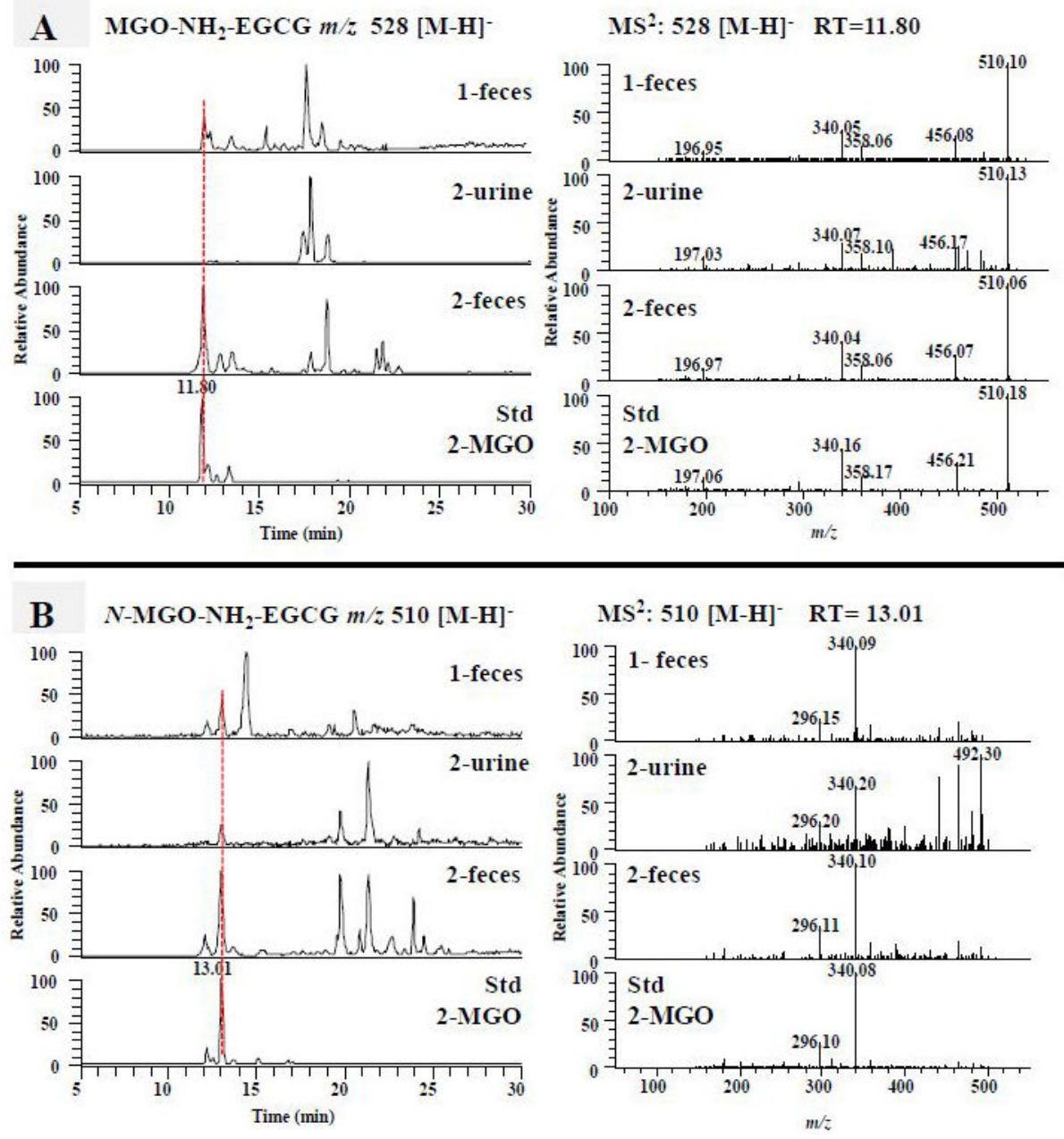

Figure 4.

The formation of the methylglyoxal (MGO) conjugated metabolites of 4'-NH 2 -EGCG in mice. The LC chromatograms and the ESI-MS ${ }^{2}$ spectra of MGO-NH 2 -EGCG $(\mathrm{m} / z 528$ [M$\left.\mathrm{H}^{-}\right)(\mathbf{A})$ and $\mathrm{N}$-MGO-NH $2-\mathrm{EGCG}\left(\mathrm{m} / \mathrm{z} 510[\mathrm{M}-\mathrm{H}]^{-}\right)(\mathbf{B})$ of mouse fecal and urinary samples collected from EGCG (1) treated mice, 4'- $\mathrm{NH}_{2}-\mathrm{EGCG}(\mathbf{2})$ treated mice, and the sample collected from chemical incubation of 4'-NH2-EGCG (2) with MGO in phosphate buffer (pH 7.4) at $37^{\circ} \mathrm{C}$ for $3 \mathrm{~h}$. 
A MDA-EGCG $m / z 529[\mathrm{M}-\mathrm{H}]^{-}$

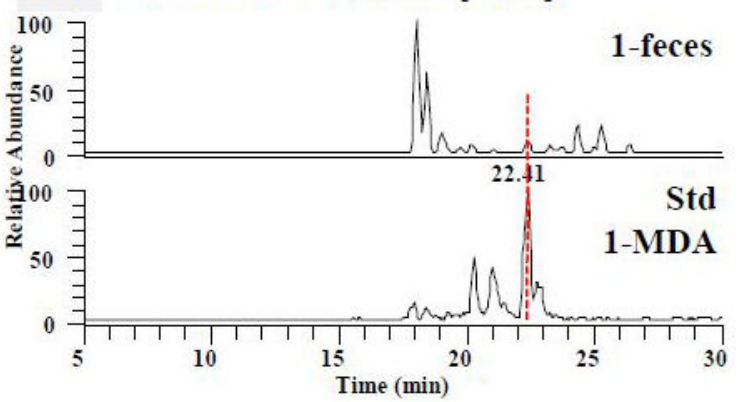

\section{B MDA-NH - -EGCG $m / z 528[\mathrm{M}-\mathrm{H}]^{-}$}

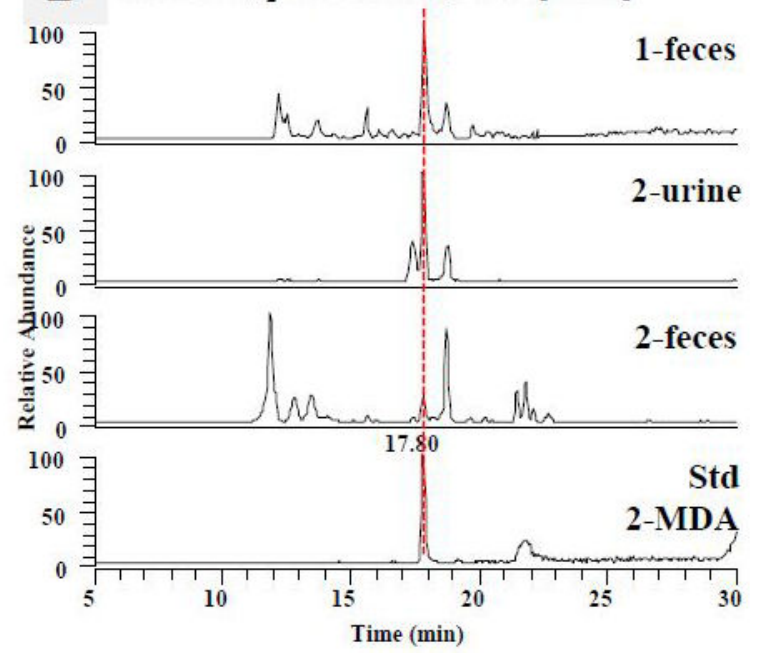

$M^{2} \mathbf{2} 528[\mathrm{M}-\mathrm{H}]^{-} \quad$ RT $=17.8$

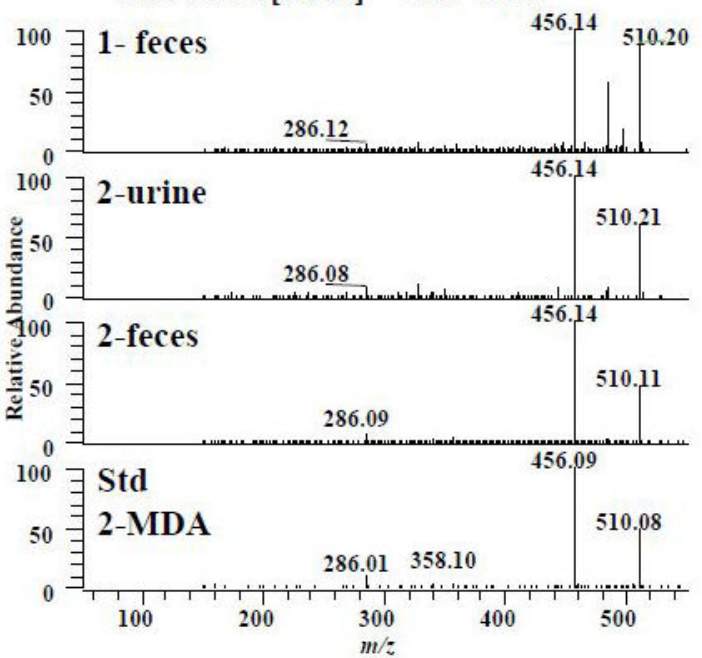

Free Radic Biol Med. Author manuscript; available in PMC 2020 February 01. 

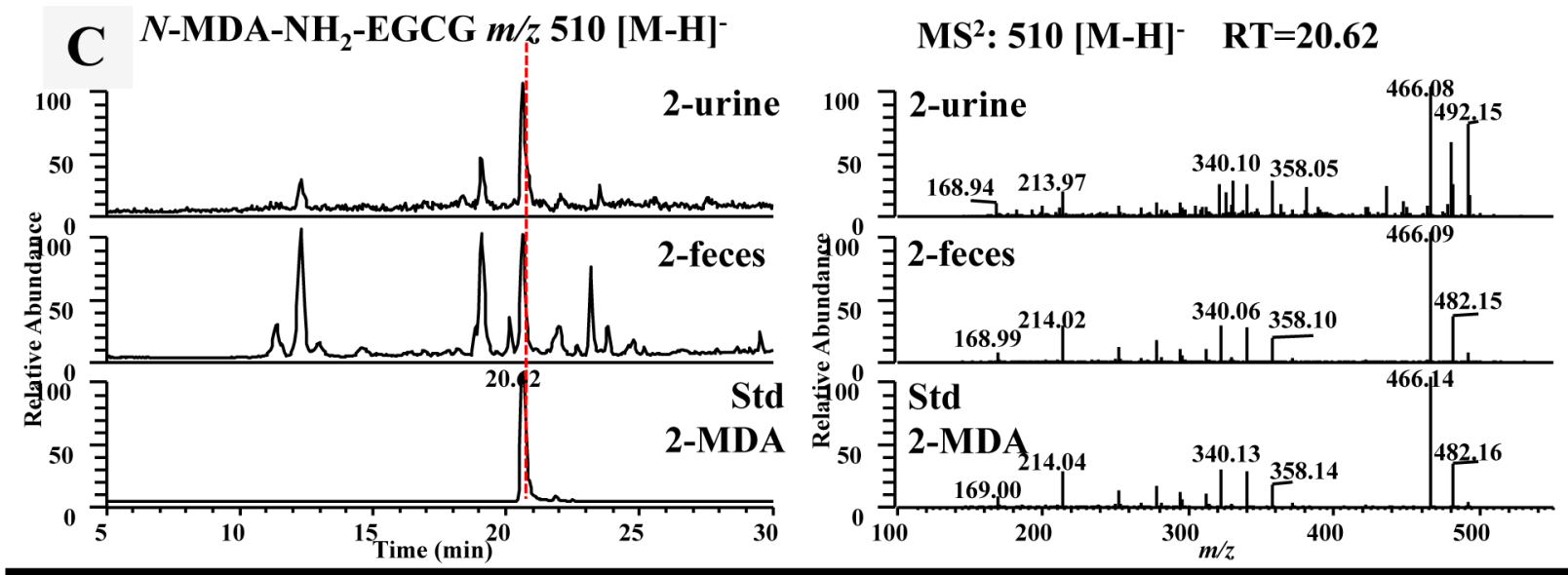

\section{HNE-EGCG $m / z 595[M-H]^{-}$}
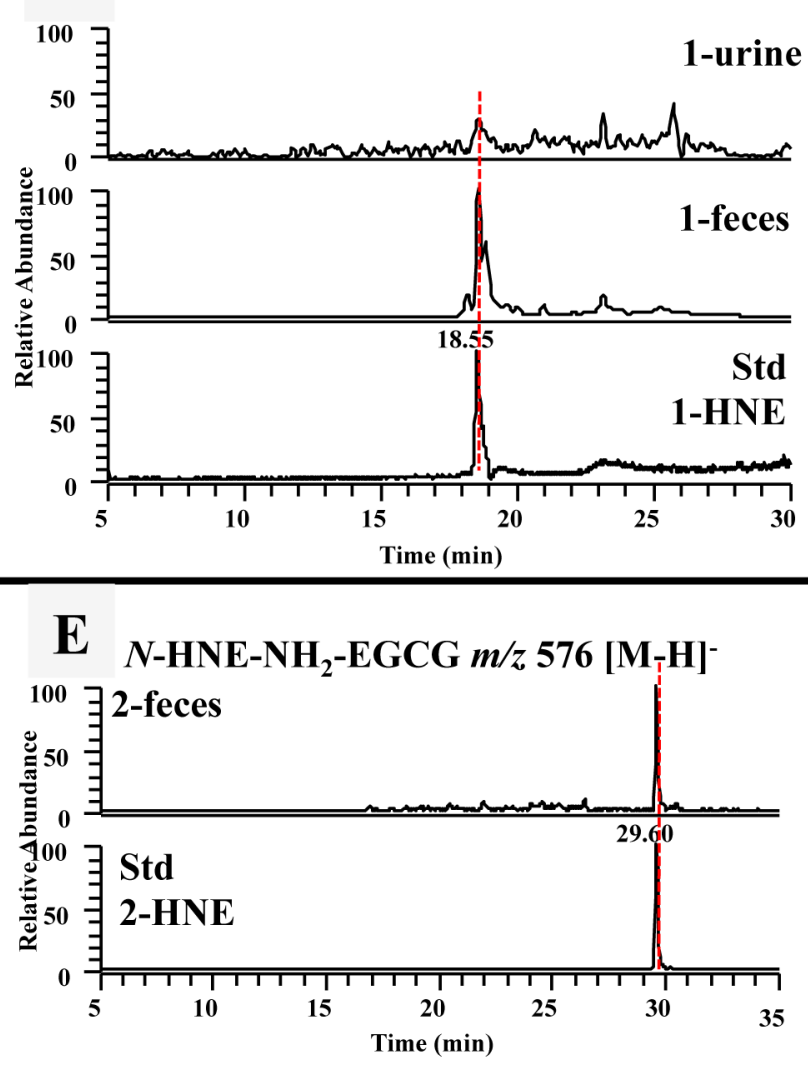
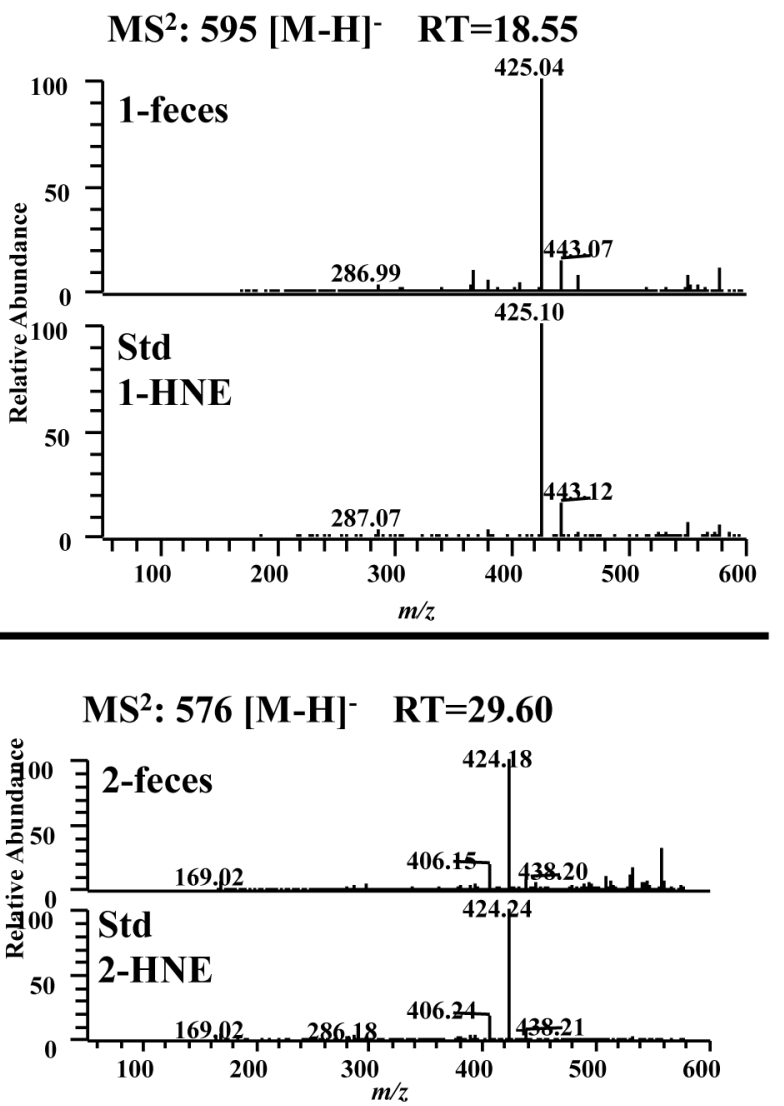

Figure 5.

The formation of the malondialdehyde (MDA) and 4-hydroxy-trans-2-nonenal (4-HNE) conjugated metabolites of EGCG and 4'-NH 2 -EGCG in mice. (A) The LC chromatograms and the ESI-MS ${ }^{2}$ spectra of mono MDA-EGCG $\left(\mathrm{m} / z 529[\mathrm{M}-\mathrm{H}]^{-}\right)$of mouse fecal samples collected from EGCG (1) treated mice and the sample collected from chemical incubation of EGCG (1) with MDA in phosphate buffer ( $\mathrm{pH} 7.4$ ) at $37^{\circ} \mathrm{C}$ for $6 \mathrm{~h}$. The LC chromatograms and the ESI-MS ${ }^{2}$ spectra of MDA-NH $2_{2}$-EGCG $\left(\mathrm{m} / \mathrm{z} 528[\mathrm{M}-\mathrm{H}]^{-}\right)(\mathbf{B})$ and $\mathrm{N}$-MDA-4'-NH $2^{-}$ EGCG $\left(\mathrm{m} / z 510[\mathrm{M}-\mathrm{H}]^{-}\right)(\mathbf{C})$ of mouse fecal and urinary samples collected from EGCG (1) treated mice, 4'-NH $\mathrm{NH}_{2}$-EGCG (2) treated mice, and the sample collected from chemical 
incubation of 4'-NH${ }_{2}$-EGCG (2) with MDA in phosphate buffer (pH 7.4) at $37{ }^{\circ} \mathrm{C}$ for $6 \mathrm{~h}$. (D) The LC chromatograms and the ESI-MS ${ }^{2}$ spectra of mono HNE-EGCG $(\mathrm{m} / \mathrm{z} 595$ [M-H] -) of mouse urinary and fecal samples collected from EGCG (1) treated mice and the sample collected from chemical incubation of EGCG (1) with HNE in phosphate buffer (pH 7.4) at $37^{\circ} \mathrm{C}$ for $6 \mathrm{~h}$. (E) The LC chromatograms and the ESI-MS ${ }^{2}$ spectra of $\mathrm{N}$-HNE-4'-NH $\mathrm{N}_{2}-$ EGCG $\left(\mathrm{m} / \mathrm{z} 576[\mathrm{M}-\mathrm{H}]^{-}\right)$of mouse fecal samples collected from 4'-NH ${ }_{2}$-EGCG (2) treated mice and the sample collected from chemical incubation of $4{ }^{\prime}-\mathrm{NH}_{2}$-EGCG (2) with HNE in phosphate buffer ( $\mathrm{pH} 7.4)$ at $37^{\circ} \mathrm{C}$ for $6 \mathrm{~h}$. 

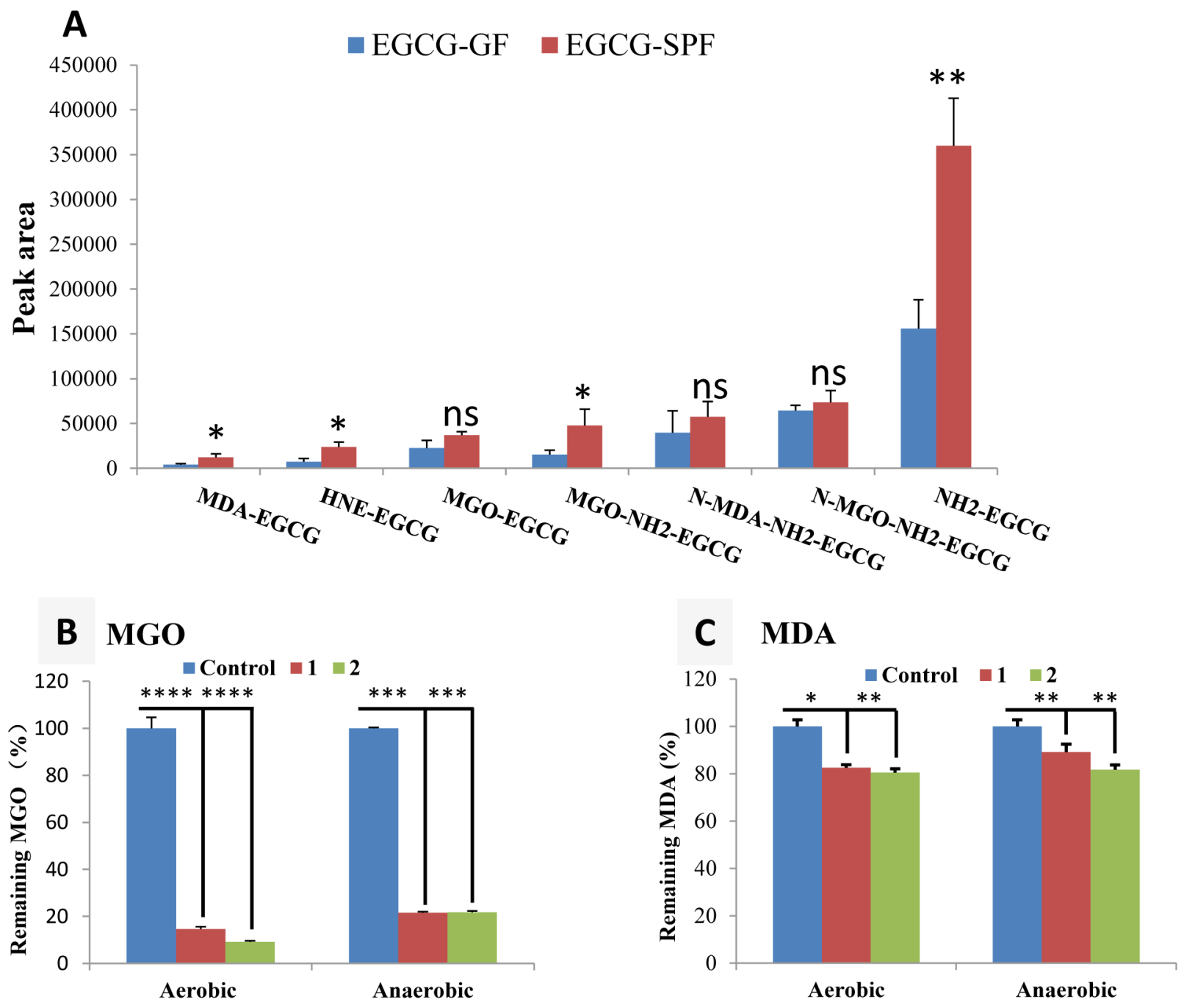

Figure 6.

The impacts of gut microbiota and oxygen on the scavenging capacity of EGCG. (A) the average of peak areas of the metabolites of EGCG (4'-NH 2 -EGCG, MGO-EGCG, MGO$\mathrm{NH}_{2}$-EGCG, $N$-MGO-NEE-EGCG. MDA-EGCG, $N$-MDA-NH 2 -EGCG. and HNE-EGCG) from fecal samples collected from EGCG treated GF and SPF mice. Data are presented as the means \pm standard deviation of three replications. A 2-tailed Student's $t$ test distribution with paired groups was evaluated for statistical significance. $p>0.05$ was considered not significant (ns), and $* p<0.05$ and $* * p<0.005$ were considered statistically significant. (B, C) Trapping of MGO $(200 \mu \mathrm{M})$ and MDA $(200 \mu \mathrm{M})$ by EGCG $(600 \mu \mathrm{M})$ and 4 '-NH 2 -EGCG $(600 \mu \mathrm{M})$ in phosphate buffer (pH 7.4 and $\left.37^{\circ} \mathrm{C}\right)$ at $6 \mathrm{~h}(\mathrm{MGO})$ and $12 \mathrm{~h}$ (MDA). Data are presented as the means \pm standard deviation of three replications. A 2-tailed Student's $t$ test distribution with paired groups was evaluated for statistical significance. $* p<0.05$, ** $p<$ $0.005, * * * p<0.001$, and $* * * * p<0.0001$. 


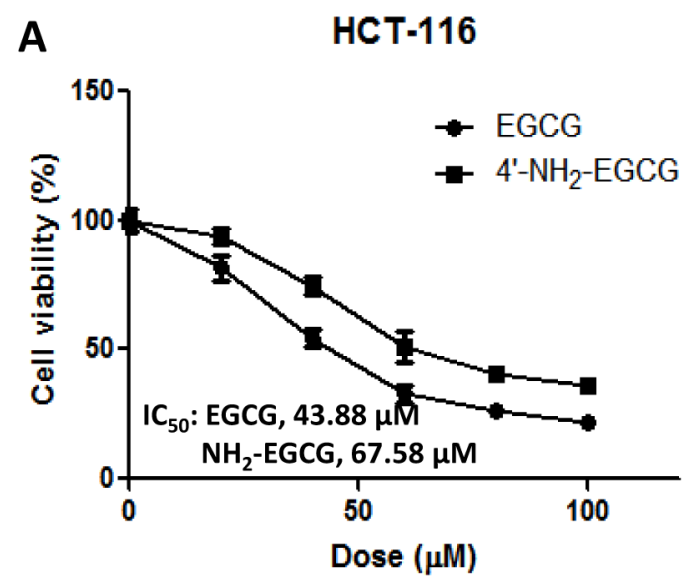

HT-29

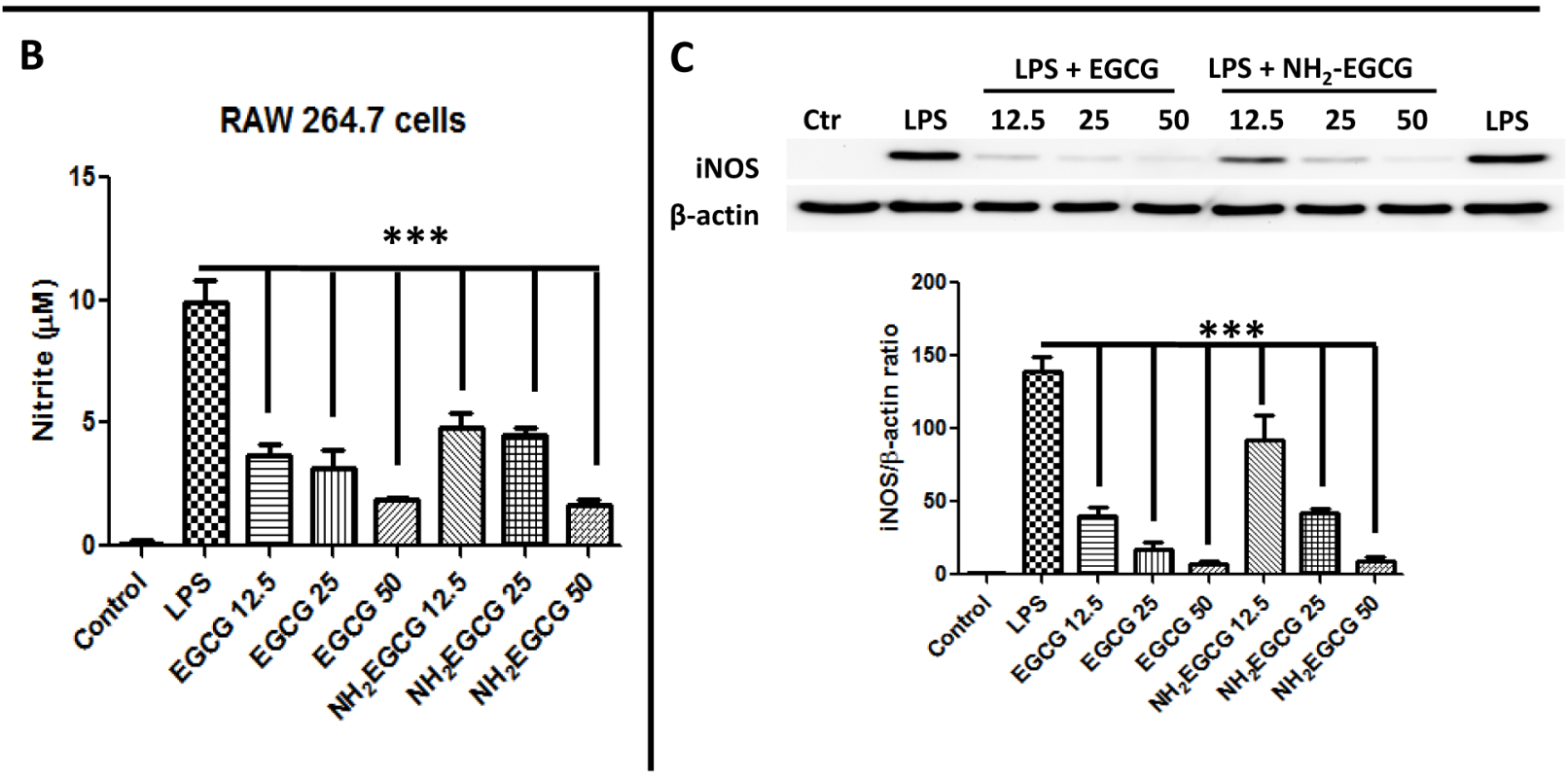

Figure 7.

The animated metabolite, 4'- $\mathrm{NH}_{2}$-EGCG, retains the bioactivity of EGCG. (A) Growth inhibition of EGCG and 4'-NH $\mathrm{NH}_{2}$-EGCG against human colon cancer cells HCT-116 and HT-29. MTT assays: cells were treated with $0,20,40,60,80$, and $100 \mu \mathrm{M}$ concentrations of the test compounds for $48 \mathrm{~h}$ in the presence of $10 \% \mathrm{FBS}$ and $1 \%$ streptomycin/penicillin at $37^{\circ} \mathrm{C}$. Bar, standard error $(\mathrm{n}=6)$. (B) Anti-inflammatory effects of EGCG and 4'- $\mathrm{NH}_{2}$ EGCG in murine RAW 264.7 macrophages. RAW 264.7 cells were pretreated with different doses of EGCG and 4'-NH $\mathrm{NH}_{2}$-EGCG for $1 \mathrm{~h}$ and then with $100 \mathrm{ng} / \mathrm{mL}$ of LPS with different concentrations of EGCG and 4'-NH $\mathrm{N}_{2}$-EGCG for another $23 \mathrm{~h}$. The production of NO was assayed in the culture medium using Griess reagent. (C) the expression of iNOS was detected by Western blot. Quantification of iNOS was normalized to $\beta$-actin. These experiments were repeated three times with similar results. The values are expressed as means \pm standard deviation. $(*) \mathrm{p}<0.05,\left({ }^{* *}\right) \mathrm{p}<0.01,\left({ }^{* *}\right) \mathrm{p}<0.001$ indicate statistically significant differences from the LPS-treated group. 
<smiles>O=C(O[C@H]1Cc2c(O)cc(O)cc2O[C@H]1c1cc(O)c(O)c(O)c1)c1cc(O)c(O)c(O)c1</smiles>

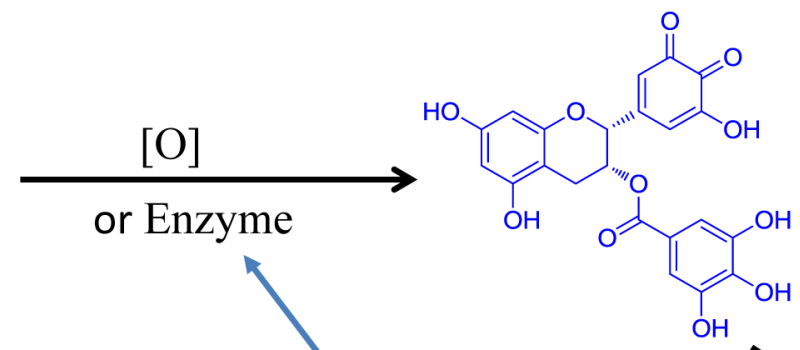

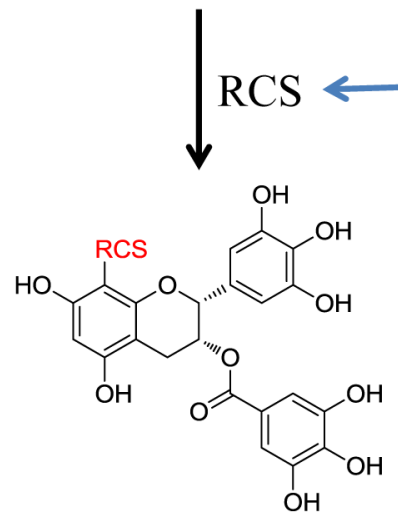

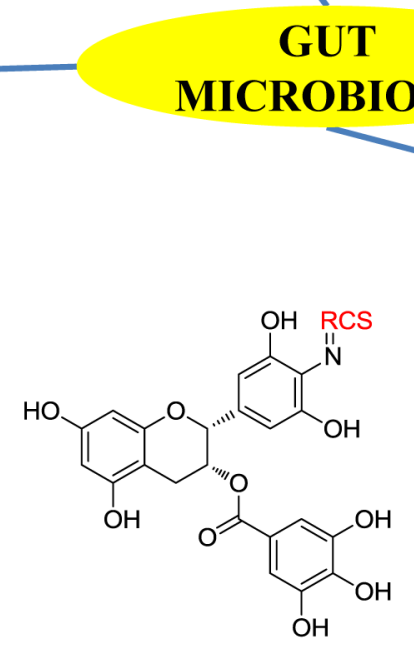

Figure 8.

The impact of gut microbiota on the metabolic pathways for the formation of the aminated and the RCS conjugated EGCG metabolites. RCS: reactive carbonyl species. 
Table 1.

${ }^{1} \mathrm{H}-(400 \mathrm{M} \mathrm{Hz})$ and ${ }^{13} \mathrm{C}-\mathrm{NMR}(100 \mathrm{M} \mathrm{Hz})$ data of 4'-NH2-EGCG (2) and EGCG (1) and HMBC correlations of 4 '-NH 2 -EGCG (2).

\begin{tabular}{|c|c|c|c|c|c|}
\hline \multirow[t]{3}{*}{ position } & \multicolumn{3}{|c|}{2} & \multicolumn{2}{|l|}{1} \\
\hline & $\delta_{H}$ & $\delta_{C}$ & HMBC & $\delta_{H}$ & $\delta_{C}$ \\
\hline & $\delta(\mathbf{p p m}), J(\mathbf{H z})$ & $\delta(\mathbf{p p m})$ & & $\delta(\mathbf{p p m}), J(\mathbf{H z})$ & $\delta(\mathbf{p p m})$ \\
\hline 2 & $4.87(1 \mathrm{H}, \mathrm{s})$ & 77.0 & $3,4,8 \mathrm{a}, 1^{\prime}, 2^{\prime}, 6^{\prime}$ & $4.88(1 \mathrm{H}, \mathrm{s})$ & 76.9 \\
\hline 3 & $5.24(1 \mathrm{H}, \mathrm{s})$ & 68.7 & $2,4,4 \mathrm{a}, 7 "$ & $5.28(1 \mathrm{H}, \mathrm{s})$ & 68.5 \\
\hline \multirow[t]{2}{*}{4} & $2.57(1 \mathrm{H}, \mathrm{d}, 16.5)$ & 26.1 & $2,3,4 a, 5,8 a$ & $2.57(1 \mathrm{H}, \mathrm{d}, 15.8)$ & 26.2 \\
\hline & $2.84(1 \mathrm{H}, \mathrm{dd}, 4.5,16.7)$ & & & $2.85(1 \mathrm{H}, \mathrm{d}, 16.0)$ & \\
\hline $4 a$ & & 97.8 & & & 97.8 \\
\hline 5 & & $157.0^{a}$ & & & $157.0^{b}$ \\
\hline 6 & $5.85(1 \mathrm{H}, \mathrm{s})$ & 96.0 & $5,7,8,4 \mathrm{a}$ & $5.85(1 \mathrm{H}, \mathrm{s})$ & 96.0 \\
\hline 7 & & $156.9^{a}$ & & & $156.9^{b}$ \\
\hline 8 & $5.74(1 \mathrm{H}, \mathrm{s})$ & 94.8 & $7,8 \mathrm{a}, 4 \mathrm{a}, 6$ & $5.75(1 \mathrm{H}, \mathrm{s})$ & 94.8 \\
\hline $8 \mathrm{a}$ & & 156.1 & & & 156.1 \\
\hline $1^{\prime}$ & & 127.7 & & & 129.1 \\
\hline $2^{\prime} / 6^{\prime}$ & $6.35(2 \mathrm{H}, \mathrm{s})$ & $105.5(2 \mathrm{C})$ & $1^{\prime}, 2,3^{\prime}, 5^{\prime}, 4^{\prime}$ & $6.32(2 \mathrm{H}, \mathrm{d}, 2.3)$ & 105.9 \\
\hline $3^{\prime} / 5^{\prime}$ & & $145.3(2 \mathrm{C})$ & & & 145.8 \\
\hline $4^{\prime}$ & & 122.1 & & & 132.8 \\
\hline $1 "$ & & 119.7 & & & 119.7 \\
\hline $2 " / 6 "$ & $6.76(2 \mathrm{H}, \mathrm{s})$ & $109.1(2 \mathrm{C})$ & 1", 3", 5", 4", 7" & $6.73(2 \mathrm{H}, \mathrm{d}, 2.2)$ & 109.1 \\
\hline 3"/5" & & $145.8(2 \mathrm{C})$ & & & 146.1 \\
\hline $4 "$ & & 138.9 & & & 138.9 \\
\hline 7" & & 165.8 & & & 165.7 \\
\hline
\end{tabular}

Free Radic Biol Med. Author manuscript; available in PMC 2020 February 01. 